\title{
Gradhiva
}

GRADHI

Revue d'anthropologie et d'histoire des arts

$10 \mid 2009$

Présence africaine

\section{La maison Présence Africaine}

Home of Présence Africaine

\section{Marc-Vincent Howlett et Romuald Fonkoua}

\section{(2) OpenEdition}

Journals

Édition électronique

URL : http://journals.openedition.org/gradhiva/1537

DOI : $10.4000 /$ gradhiva. 1537

ISSN : 1760-849X

\section{Éditeur}

Musée du quai Branly Jacques Chirac

\section{Édition imprimée}

Date de publication : 4 novembre 2009

Pagination : 106-133

ISBN : 978-2-35744-012-8

ISSN : 0764-8928

Référence électronique

Marc-Vincent Howlett et Romuald Fonkoua, «La maison Présence Africaine », Gradhiva [En ligne], 10 | 2009, mis en ligne le 04 novembre 2012, consulté le 21 décembre 2020. URL : http:// journals.openedition.org/gradhiva/1537 ; DOI : https://doi.org/10.4000/gradhiva.1537 


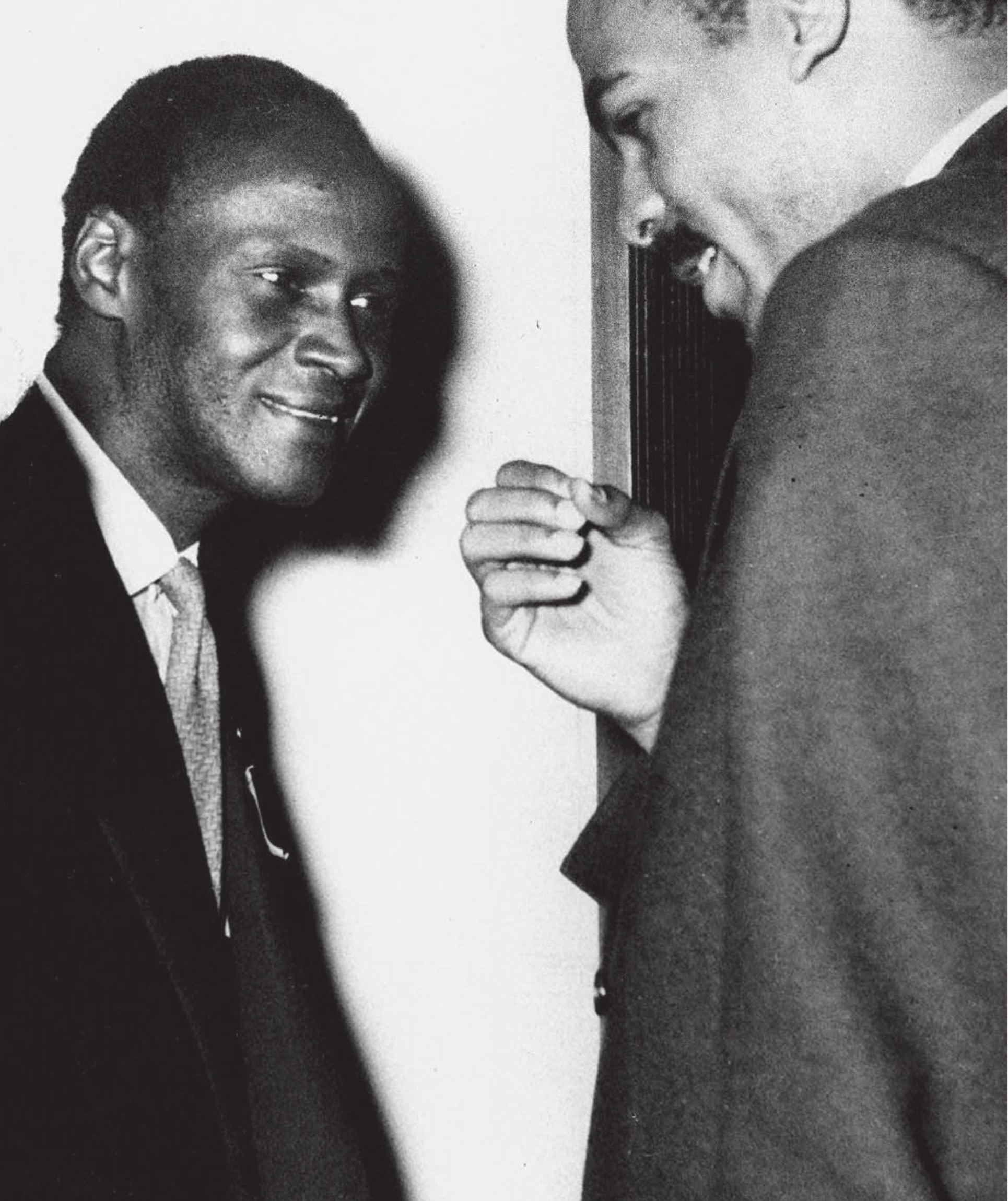




\section{La maison Présence Africaine}

\section{Marc-Vincent Howlett et Romuald Fonkoua}

Fig. 1 Édouard Glissant et Alioune Diop au Second Congrès des écrivains et artistes noirs à Rome, mars-avril 1959 (c) Présence Africaine.
Une entreprise à nulle autre pareille

Il fallait le courage et la vision prophétique des glorieux aînés de Présence Africaine pour que cette aventure puisse connaitre un autre destin que celui d'une énième revue rassemblant un collectif d'intellectuels ou de militants de la cause noire en France. Car, des revues et des collectifs, il y en eut, et tous ont connu une durée de vie limitée à ce que leurs rédacteurs étaient capables de partager; or, nous savons que ces revues, ces bulletins et ces collectifs ne vivent que le temps des alliances suscitées par le présent et périclitent au rythme des secousses de l'histoire et à l'aune des ambitions de quelques-uns. Présence Africaine s'inscrit dans cette histoire, mais, dans le même temps, s'en affranchit en construisant un espace de discours spécifique. Présence Africaine est à la fois un héritage et une naissance: Présence Africaine n'a pas plus créé le mouvement de la négritude qu'elle n'a suscité, en toutes lettres, la présence de la parole africaine, pas plus également qu'elle n'a été le lieu fédérateur de toutes ces énergies émancipatrices qui clamaient haut et fort la reconnaissance de l'Afrique, bref, elle n'a pas été une parmi d'autres ou l'une pour les autres, car elle a été une.

Pour mieux comprendre ce qu'est Présence Africaine, empruntons aux mathématiciens ce qu'ils appellent une «intégrale». Présence Africaine a voulu parler au nom de la loi de l'intérêt commun de la série des discours noirs : elle n'a pas voulu construire la somme de ces discours, mais, plutôt, la somme de leurs différences. C'est en cela que Présence Africaine est spécifique. Elle n'aurait pu durer si elle n'avait été que le cénacle d'une parole massive et sans relief, supposée, au titre d'un dénominateur commun, fédératrice de paroles disséminées. Pas plus elle ne s'est voulue parole partisane. Présence Africaine a joué de la multiplicité de ces (ses) voix sans se perdre dans la stricte singularité de chacune. Mais, pour 


\section{LES CONDITIONS NOIRES : UNE GÉNÉALOGIE DES DISCOURS}

que cette opération réussisse, il fallait que les différences existent en tant que telles et, surtout, qu'elles ne soient pas trop radicales afin d'éloigner le spectre de l'éclatement et, probablement, de l'impuissance. La contradiction ne pouvait être absolue sans que celui qui la portait prenne le risque de ne plus être entendu au sein de la maison. Dans cette maison - car il n'y a point d'autres mots pour qualifier cette demeure qui tient autant de la famille que de l'hospitalité de l'étranger-, chacun a su qu'il participait à une œuvre qui le dépassait. Il fallait donc que la contradiction, quand elle existait, fût d'abord au service des desseins de la maison. C'est en cela qu'au nom d'un intérêt supérieur - ne pas céder sur la cause noire - elle était une...

Une en ceci donc qu'elle a été le lieu unique de toutes ces paroles et qu'elle en a constitué tant le lieu de rencontre que le foyer de leur contestation. Le un de Présence Africaine est moins le fief d'un pouvoir hégémonique que l'espace des paroles multiples, différentes, controversées, un lieu où une pensée africaine pouvait s'affirmer dans la confusion des voies comme dans la nécessité d'une existence. Présence Africaine n'avait pas tant à être le dépositaire d'un savoir sur l'Afrique que le terrain de construction de ce savoir et, en cela, elle se tenait au temps des recommencements après l'obscure et désastreuse négation coloniale. Recommencer parce que tous ceux qui fondèrent Présence Africaine savaient que l'Afrique avait déjà commencé, qu'elle n'était pas seulement ce continent surgi dans l'histoire de l'Occident à l'occasion de la traite et de la colonisation, un continent naissant à l'histoire à l'aune de ce que l'Occident avait conçu de l'histoire universelle, mais un espace politique et un foisonnement de cultures qui se conjuguaient dans le champ d'histoires, de cultures et de civilisations. Recommencer à parler de l'Afrique consistait à clamer haut et fort, par conséquent, qu'elle avait une parole, que cette parole - longtemps niée, bafouée, refoulée - ne pouvait se satisfaire d'être commentée, manipulée, réécrite par ceux-là mêmes qui l'avaient dévoyée ou interdite, mais qu'elle devait être réinscrite dans un champ d'étude et de contributions qui pourrait ainsi conforter l'idée d'une existence et d'une histoire de cultures africaines. Par-delà les incantations et les idées mobilisatrices, Présence Africaine a voulu que l'Afrique ne soit plus la terre des explorateurs et des colonisateurs, celle d'un Occident en quête de nouvelles richesses ou celle d'un Occident en mal de fantasmes exotiques, mais le lieu d'une histoire se faisant. Le passé n'avait de valeur que pour construire l'avenir; explorer ces cultures africaines n'avait de sens que si elles étaient, non pas pensées à l'échelle de nos critères culturels occidentaux, mais comprises dans leur spécificité, en dehors notamment de la funeste procédure de l'évaluation.

Dire de Présence Africaine qu'elle fut une n'implique pas la moindre domination ou la moindre prédominance d'une pensée hégémonique. Il suffit de lire ses premières contributions, ainsi que la liste de son comité de parrainage, pour se rendre compte que les sensibilités politiques et idéologiques y furent nombreuses et variées : on y rencontre autant de chrétiens que de compagnons de route du Parti communiste, autant de déçus du Parti communiste que d'adeptes de l'universalisme teilhardien, autant de spiritualistes que de matérialistes; bref, des rencontres improbables qui, finalement, devaient faire événement. Si ces hommes et ces femmes se sont rencontrés à et dans Présence Africaine, c'est parce qu'ils ne pouvaient plus accepter l'humiliation faite à l'Afrique. Alioune Diop le réaffirmera avec force dans son discours lors du Second Congrès à Rome : «Nulle autre race de couleur (que la Nègre) n'a joué un rôle aussi humiliant dans la culture occidentale, nulle ne fit au même degré l'expérience de l'esclavage » (A. Diop 1959). 


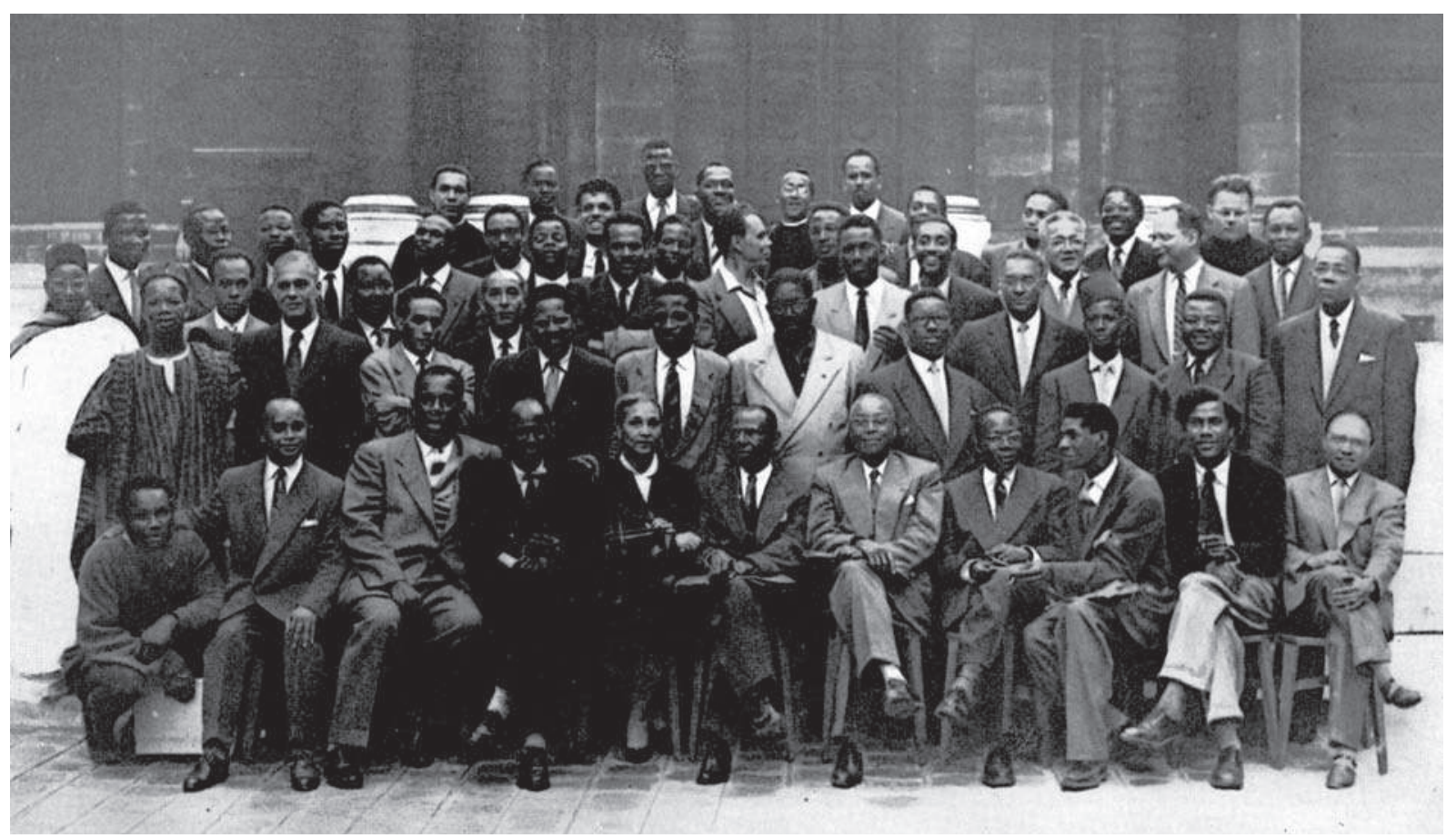

Qui veut entendre la voix africaine ne peut s'exempter d'en saisir la double origine : l'humiliation et la culture. La culture pour échapper à cette humiliation que des siècles de domination et d'exploitation ont exercée sur ce continent.

Le mot salvateur sera celui de «culture». Non pour rivaliser avec la culture triomphante de l'Occident, mais pour faire connaître les richesses et les potentialités des cultures africaines et, en même temps, réfléchir, au miroir de ces cultures oubliées et bafouées, aux implications historiques et politiques de celle qui les a spoliées. Même si Présence Africaine n'a pas vocation à s'interroger sur les cultures occidentales, elle ne peut les ignorer et ne peut en retour les questionner. C'est la raison pour laquelle Présence Africaine est également un lieu de débats, car, pour ceux qui savent lire, il est clair que le terme "culture " est à ce point polymorphe qu'il ne peut qu'engager recherches et débats, voire controverses. Tantôt, pris dans les rets de l'entreprise coloniale, l'étendard de la culture sera synonyme de domination; tantôt, figure mobilisatrice de valeurs de reconnaissance, il sera vertu révolutionnaire. Car ce n'est pas le moindre des paradoxes que ce terme de "culture" tant honni des consciences marxistes qui ne pensaient qu'en termes de lutte des classes se soit avéré porteur de vertus révolutionnaires. Même le très beau texte de Sartre «Orphée noir » (1949) a trouvé des contradicteurs véhéments dans les rangs du Parti communiste dénonçant dans la négritude, ainsi pensée par Sartre, une énième mystification. La culture africaine, même parmi ceux qui, au sein de la colonisation, lui accordaient une place, était en réalité enterrée au profit des intérêts supérieurs de la colonisation et des valeurs universalistes de l'Occident. Rares sont ceux qui pouvaient conférer à cette culture africaine une valeur autre que muséale (au mieux dans le musée de l'Homme, au pire dans des expositions dites universelles) et lui accorder une force politique et révolutionnaire - en un mot, dynamique.
Fig. 2 Photographie des participants au Premier Congrès international des écrivains et artistes noirs à Paris, septembre 1956 @ Présence Africaine. 
Rien n'est plus saisissant que les débats suscités au sein de la revue par les événements politiques qui marquèrent la lutte pour les indépendances : Bandung (1955) sera à cet égard un événement révélateur qui marquera fortement les débats lors du Premier Congrès des écrivains et artistes noirs.

Personne ne pouvait contester l'autorité que, dès le début, Présence Africaine a pu représenter auprès de tous, puissances coloniales autant que forces luttant pour la décolonisation. Cette autorité venait paradoxalement de son absence d'«idéologie philosophique ou politique»; elle n'avait pas de parti derrière elle et s'autorisait d'une certaine absence de l'Afrique dans le vaste conflit qui avait secoué le monde en ce milieu de $\mathrm{xx}^{\mathrm{e}}$ siècle pour faire appel aux «hommes de bonne volonté ». N'être pas engagé directement, du moins n'être pas partie prenante, dans la guerre et subir, par la colonisation, la face mortifère de l'Europe laissaient à ces intellectuels africains la possibilité de saisir les raisons d'un conflit et la nécessité d'une présence.

Il n'est pas étonnant que Présence Africaine ait bénéficié à son lancement d'un comité de parrainage prestigieux dans lequel se trouvaient les grandes figures de l'anti-fascisme et les premières consciences de la nécessaire décolonisation. C'est dire qu'en ces lendemains de Seconde Guerre mondiale, si une partie de l'Europe, l'URSS et les États-Unis avaient mis fin à la menace fasciste, il n'en restait pas moins que quelque chose de cette face obscure de l'humanisme occidental perdurait en ces lointains pays d'outre-mer. La colonisation était une entreprise de négation des peuples et des cultures, de pillage des ressources économiques, et la soumission assurée à des modèles de fonctionnement politique qui contribuaient à la trahison des élites. Gide, Sartre, Leiris, Monod, Mounier, Camus, Hazoumé, Senghor et Wright étaient tous des personnalités qui, de près ou de loin, avaient connu le fascisme, le colonialisme et le racisme, contre lesquels ils avaient lutté. Présence Africaine ne pouvait être qu'une parole libérée de ces trois fléaux dont une certaine idéologie française ne s'était pas totalement exemptée, au point même d'en faire sa référence.

\section{Les pensées fondatrices}

Ce triple front historico-culturel (contre le fascisme, le colonialisme et le racisme) a donc été le terreau où se sont nourries toutes les entreprises de renaissance de la culture africaine. Présence Africaine a été de tous les combats. Dans l'orbite de la négritude, la cause noire était entendue; comme l'affirmait Aimé Césaire, un objectif était posé : «C'est le Nègre qu'il fallait chercher en nous » (Césaire 2005). Ce Nègre, tant humilié, se devait d'exister en affirmant son identité. Non pas l'identité imposée par les cultures européennes, mais celle qu'il fallait redécouvrir, voire construire pour exister dans une histoire qui laissait à l'Afrique si peu de place. Cependant, l'Afrique avait trop connu toutes les formes de l'inféodation pour que les intellectuels engagés dans le combat de Présence Africaine s'inféodent de nouveau à une idéologie qui leur aurait commandé des adhésions douteuses. Bref, l'aventure avait permis que se rencontrent des intellectuels venus d'horizons divers et chacun de ces horizons possédait son lot de discours convenus auxquels on reconnaît souvent la faillite des pensées libres. Mais, en même temps, Présence Africaine était fille de son temps ; et les intellectuels qu'elle avait agrégés à son initiative avaient déjà de longs parcours qu'ils n'étaient pas près ou en mesure d'abandonner. Ainsi, des courants de pensée comme le christianisme,

Les statues meurent aussi de Chris Marker et Alain Resnais, 1953. Iconothèque de la Cinémathèque française ¿ Présence Africaine. 

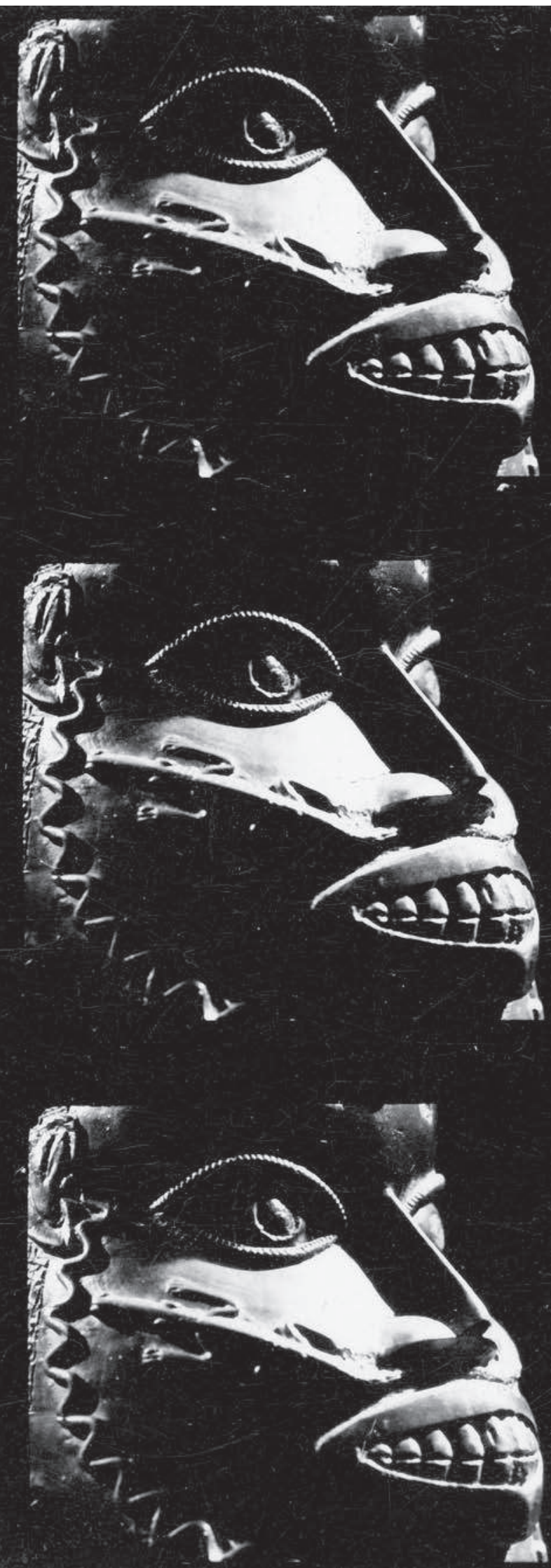
le marxisme, l'existentialisme ont eu leurs représentants, de même que s'est fait sentir le poids culturel d'institutions dont étaient issus ces intellectuels (université, École normale supérieure, musée de l'Homme, Éducation nationale, Assemblée nationale, Sénat, etc.), révélant de-ci de-là des inerties que le feu du combat culturel a mises en péril. Car seul comptait que l'Afrique fût de nouveau debout; et une telle entreprise n'était pas sans incidence sur les certitudes des uns et des autres, d'autant que chacun pouvait mesurer, avec ces pesanteurs intellectuelles et institutionnelles, la part de responsabilité qui lui incombait dans le naufrage de l'Afrique. En une phrase aussi éprouvante qu'ambitieuse, Sartre avait dessiné l'exigence à laquelle chacun à présent devait s'obliger : "Point n'est besoin d'y mettre de la colère ou de la révolte : la vérité seulement, cela suffira pour que nous recevions au visage le souffle torride de l'Afrique, l'odeur aigre de l'oppression et de la misère " (Sartre 1947).

Dans cet ensemble d'intellectuels africains, noirs américains et européens gravitant autour de Présence Africaine, une constellation de quatre personnalités a engagé à jamais Présence Africaine dans ce qui devait dessiner sa trajectoire originale : Léopold Sédar Senghor, Aimé Césaire et Léon-Gontran Damas d'une part et Alioune Diop d'autre part. Ces quatre personnalités ont formé la figure originelle, une sorte de losange, des pensées fondatrices de la maison.

Ce n'est pas tant que Senghor et Césaire aient beaucoup contribué à la revue (bien que nombre de leurs textes soient édités par Présence Africaine, à l'exception notable de ceux de Senghor, qui a préféré les éditions du Seuil), mais le mouvement de la négritude qu'ils avaient initié dans l'entre-deux-guerres allait rester l'horizon des engagements de la maison sans que cesse une passionnante déclinaison des aspects culturel et politique de cette même négritude. Et si, par ailleurs, nous mentionnons le nom d'Alioune Diop, ce n'est pas seulement en tant que fondateur de la maison - 1947 - (il est vrai que ce seul titre suffirait à en faire une figure marquante de la cause noire), mais en raison de ce que nous expliquions plus haut, à savoir le caractère irréductible de sa position par rapport aux aînés tutélaires de la négritude. Alioune Diop a construit la vision d'une Afrique délivrée de tout exotisme - on se souvient de sa mise en garde contre Madeleine Rousseau et Aimé Césaire qui faisaient l'éloge des sociétés primitives (A. Diop 1949) - vision tout entière tournée vers l'édification d'une Afrique qui serait de plain-pied avec le monde, d'une Afrique conversant d'égale à égale avec ce monde qui l'avait si longtemps ignorée. Pour cela, Alioune Diop était à l'affût de toutes les énergies créatrices, découvrant et publiant romanciers, poètes et essayistes dont les talents participaient de cette nouvelle élite africaine dont il voulait qu'elle se fondât dans l'écriture d'une nouvelle histoire. Alioune Diop a tenu le pari, au nom d'une vision humaniste de l'histoire, de penser tout à la fois l'universalisme « civilisationnel» de Senghor et la radicalité politique de Césaire. Deux universalismes se confrontaient : l'un «œcuménique» («la civilisation de l'universel») et l'autre davantage orienté vers une approche largement inspirée du marxisme. Présence Africaine a été confrontée à ce double tropisme, mais a cherché à le surmonter pour ne point y être piégée.

C'est un fait que longtemps l'idée d'universalité a séduit, au point que certains ont voulu de toute force participer à ce banquet des civilisations. Pour cela, d'aucuns ont cru qu'on se devait, faute d'y être invités, de montrer qu'on avait quelques titres à y participer. Il fallait que les pensées africaines fussent des philosophies. L'idée d'une pensée spécifiquement noire, voire d'une philosophie noire (et la publication du livre de Tempels sur la philosophie bantoue fera 
débat au sein de la maison) susceptible de se penser dans les termes d'une différence dans le champ de l'universel de la pensée, a été maintes et maintes fois reprise. Cette revendication d'une appartenance à la "civilisation de l'universel " supposait que les mêmes problématiques fussent reprises, quitte à ce que l'on en souligne les différences pour mieux en saisir les formes d'intrication et de déclinaison. Senghor a affirmé la différence entre l'Occident et l'Afrique dans les termes de la métaphysique occidentale, au point de faire de cette opposition: «L'émotion est nègre comme la raison hellène », le trait pertinent et différentiel de la spécificité des cultures africaines ("le Blanc européen est d'abord discursif, le Négro-africain d'abord intuitif»). Cette substantialisation de la pensée noire a suscité de multiples réserves et oppositions et, à cet égard, la revendication "marxiste » de Césaire a pu un moment représenter un pôle moins apparemment culturaliste et davantage politique pour nombre de collaborateurs de Présence Africaine. Cela a permis à de jeunes intellectuels de participer à tous les débats sur ce type de spécificité d'une pensée africaine, notamment sur la question de la supposée philosophie africaine, considérée par certains, comme Paulin Hountondji, comme une "ethnophilosophie", ce qui l'éloigne à ses yeux de toute philosophie et la rapproche de systèmes de pensée collective. Avec les années, le risque était immense que la négritude, figeant la culture noire en donnée réifiée, ne devienne, comme l'a craint Aimé Césaire, une idéologie capable de cautionner des confusionnismes dangereux, et elle ne pouvait se substituer, en matière de mobilisation des énergies émancipatrices, au concept de «lutte des classes» (Kesteloot et Kotchy 1993: 203-204) et à l'exemple des luttes "révolutionnaires » dans le cadre des indépendances nationales. Césaire a analysé, notamment dans la revue, la politique de Sékou Touré (Césaire 1959-1960), dont les textes politiques furent publiés à Présence Africaine (comme ceux de Nkrumah) et dont de nombreux articles ont interrogé les socialismes africains. Frantz Fanon a même pu développer dans la revue ses thèses sur les luttes de libération nationale en Afrique et a pris quelques distances avec l'idéologie de la négritude pour préférer entendre dans ces voix africaines émergentes le signe d'une nouvelle solidarité avec tous «les damnés de la terre ». Il restera jusqu'à la fin de sa vie fidèle à Présence Africaine. On se rappelle même «qu'en 1961, Fanon, malade, ayant appris qu'Alioune Diop séjournait comme lui à Washington, le fit appeler de toute urgence à son chevet pour lui transmettre son ultime message " (Kadima-Nzuji 1984).

Senghor et Césaire ont donc représenté une double polarité à l'intérieur de laquelle chacun des collaborateurs de Présence Africaine a défini sa position à la faveur de discours qui allaient de l'essai au poème. Car, et ce n'est pas une mince particularité de la revue, Présence Africaine a fait une large place à la littérature et plus particulièrement à la poésie; outre Senghor et Césaire, dont l'œuvre poétique était reconnue de tous, Présence Africaine a pu s'enorgueillir d'éditer, entre autres, Léon-Gontran Damas, haute figure de la parole poétique enracinée dans la colère des beaux chants de la douleur. Dans cette figure du losange dont le sommet reste Alioune Diop et les pôles médians Senghor et Césaire bouillonnait un autre pôle, souterrain, plus en marge, une autre parole, une révolte jamais tarie, celle de Damas, conscience tout en indignations, «feu sombre toujours " (Césaire 1979: 9), dont la fidélité à Présence Africaine ne devait jamais se démentir. Par-delà la Guyane où il était né, Léon-Gontran Damas a très tôt sensibilisé la communauté noire à la littérature noire américaine : Langston Hughes, Claude MacKay, Richard Wright. Il a vécu en partie aux États-Unis (professeur à l'université Howard de 


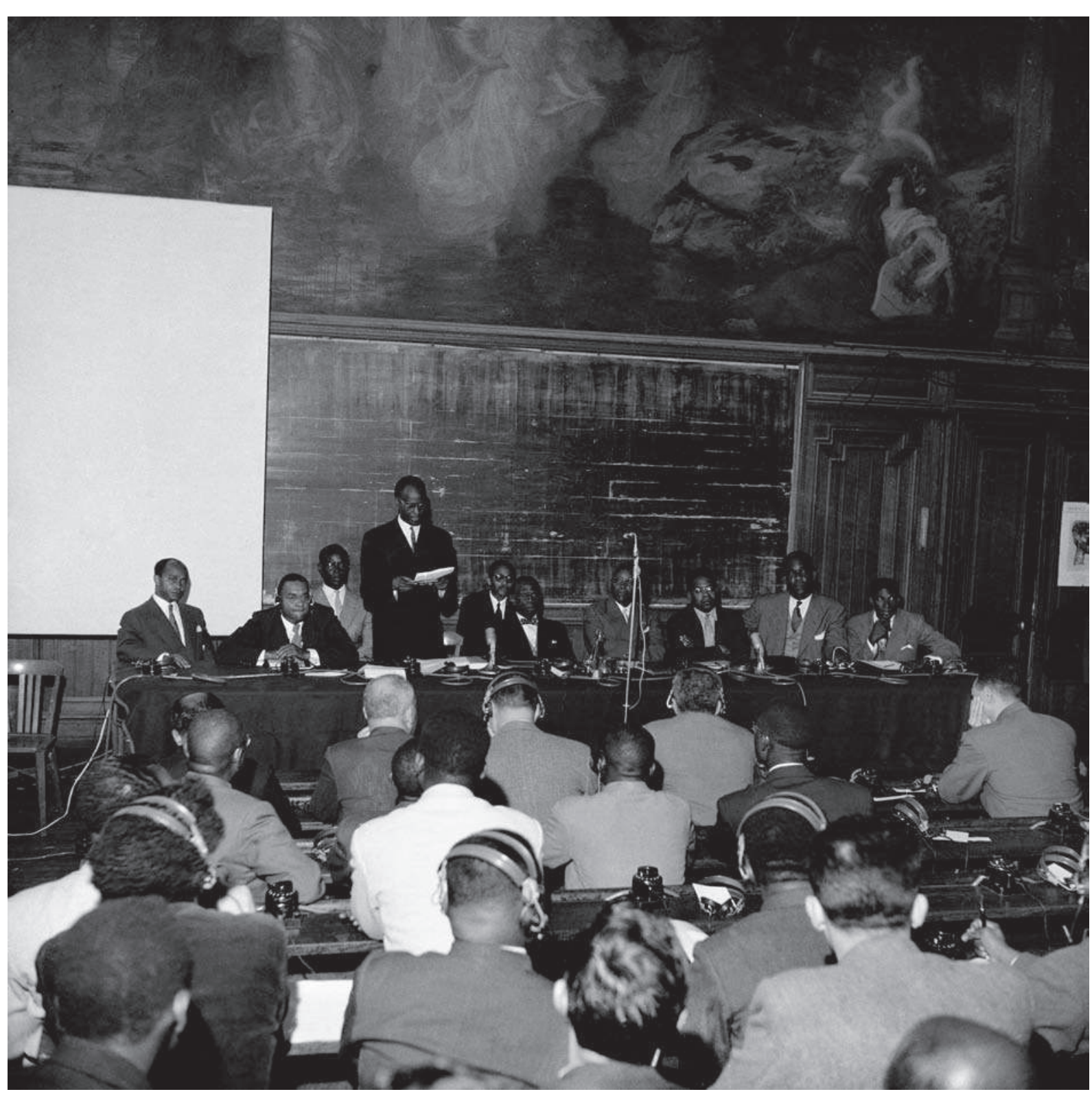

Fig. 4 Allocution d'Alioune Diop au Premier Congrès des écrivains et artistes noirs à Paris, septembre 1956 ๑) Studio Lipnitzki/ Roger-Viollet.
Washington). Grand connaisseur des poètes et romanciers noirs américains, amateur passionné de jazz et de blues, il a publié en 1947 une anthologie, Poètes d'expression française (Seuil), et donné à Présence Africaine deux recueils de poésie d'une importance capitale, Pigments et Névralgies (Damas 1972). Enfin, il a été le maître d'œuvre d'une Nouvelle somme de poésie du monde noir (Damas 1966).

Ces quatre figures ont dessiné les contours des problématiques dans lesquelles allaient s'écrire les travaux publiés dans Présence Africaine. Rares sont les textes de la maison qui peuvent s'exempter d'être, peu ou prou, redevables de cette figure à quatre pôles. Ils ont traversé toute l'histoire de Présence Africaine, présents dans tous les combats, politiques et culturels, engageant, soutenant et accompagnant Présence Africaine dans de multiples manifestations prestigieuses au rayonnement international exceptionnel : on pense, entre autres, au 
Premier Congrès des écrivains et artistes noirs à la Sorbonne en 1956, au Second Congrès à Rome en 1959, à la création de la Société africaine de culture (SAC) en 1957 ou au Festival des arts nègres de Dakar en 1966.

\section{Les nouveaux récits : histoire et littérature mêlées}

Dès 1953, Présence Africaine va prendre sa vitesse de croisière et accéder à l'autonomie qui lui permettra de remplir les tâches que lui avait assignées son fondateur, Alioune Diop : être tout à la fois un "manifeste " et un "programme». Un long manifeste : le cri de l'homme noir et singulièrement de l'homme africain, à qui l'on avait dénié, on le sait, durant de longs siècles, sa qualité d'être et de personne. Un vaste programme : «accueillir tout ce qui a trait à la cause des Noirs, et toute voix du peuple noir qui lui paraisse mériter d'être entendue »-comme l'avait bien compris Gide (Gide 1947). Pour l'ancien professeur de lettres du lycée Pothier d'Orléans, soucieux des mots et sensible à leur valeur, il s'agissait d'afficher dans un écrit le sujet d'une action et les noms de ceux qui la représentent; de faire advenir par une publicité adéquate, par un discours, si possible rationnel, la réalité nouvelle de l'être noir, de sa culture et de sa civilisation. Le manifeste, dont la portée était immédiate, devait trouver dans la politique de la culture un lieu privilégié d'expression, un moyen d'action concrète indéniable. Le programme, plus ambitieux parce qu'il devait tenir sur une longue durée - à la différence des entreprises précédentes créées par des Noirs à Paris, notamment dans l'entredeux-guerres -, consistait à créer et à donner à voir concrètement, par le récit et par l'écrit, les objets de cette nouveauté.

\section{L'écriture de l'histoire}

Cet intérêt pour l'écrit et le récit va prendre une première forme concrète dans le champ de la discipline historique. Le souci pour l'histoire s'explique aisément, on le sait, par le fait que, parmi les nombreux arguments qui ont justifié la marginalisation du continent noir, son exploitation, la réduction en esclavage de ses populations, la pratique de la colonisation et la déshumanisation du Nègre, il y a la négation de l'histoire de l'Afrique, le refus de reconnaître à l'Africain une quelconque histoire, la substitution à cette non-histoire supposée d'une autre dont la haute qualité de civilisation paraissait plus évidente. Pour les intellectuels négro-africains, selon une dénomination revendiquée à cette époque, il fallait faire pièce à l'idée couramment admise depuis Hegel que l'Afrique n'avait pas d'histoire : "qu'elle n'était pas une partie historique du monde"; qu'elle n'avait pas «de développements à montrer, de mouvements historiques en elle». "Ce que nous entendons précisément par l'Afrique, écrivait l'auteur du Cours sur la philosophie de l'histoire en 1830, est l'esprit anhistorique, l'esprit non développé, encore enveloppé dans des conditions de naturel et qui doit être présenté ici seulement comme au seuil de l'Histoire du monde."

Le programme de l'historiographie africaine sera consacré à la mise en relief de ses différents aspects scientifiques. L'historien africain va s'employer à déconstruire les formes idéologiques des savoirs européens. La figure la plus importante est celle de Cheikh Anta Diop. Son œuvre, Nations nègres et cultures, reste aujourd'hui encore le best-seller qu'il fut dès sa publication en 1954 par la maison 


\section{LES CONDITIONS NOIRES : UNE GÉNÉALOGIE DES DISCOURS}

d'édition Présence Africaine ${ }^{1}$. Cet ouvrage est le fruit de longs travaux de recherche commencés par son auteur au lendemain de la guerre, c'est-à-dire en même temps que naissait la revue. Il n'est pas nécessaire ici d'en faire l'exégèse. On rappellera cependant que ce texte doit son succès, à l'époque, autant à l'opposition de certains intellectuels et historiens français métropolitains, convaincus - bien à tort - que le discours de Cheikh Anta Diop ne reposait sur aucune base scientifique solide, à la conscience de la menace que ce nouveau discours faisait peser sur le savoir européen et ses certitudes qu'à la qualité indéniable des recherches scientifiques de son auteur. Car, si la thèse de Cheikh Anta Diop s'oppose à nombre de discours consacrés à l'Afrique au cours du xix ${ }^{e}$ siècle, c'est en raison de la qualité de sa démonstration : tirer toutes les conclusions logiques des différentes observations faites par les savants européens les plus divers - français, anglais ou allemands - depuis la rencontre des cultures et des civilisations; ne pas s'éloigner des résultats des travaux européens, mais les suivre au plus près de leur propre logique. En ce sens, il inaugure une pratique du discours qui consiste à miner l'ennemi de l'intérieur de sa propre civilisation, à adopter la position du traitre objectif à la science européenne. À partir de sources identiques, il tire des conclusions éloignées de celles sur lesquelles, par la science, l'Occident avait bâti sa puissance.

Par la qualité de ses travaux, Cheikh Anta Diop faisait ainsi la démonstration que la science n'avait pas de valeur en soi; que sa neutralité prétendue était un leurre; que l'Africain était non seulement capable de produire un discours, mais que celuici pouvait être logique. Il soutenait subrepticement l'adage auquel Alioune Diop se référait constamment au cours de cette période, à savoir : «Mange pour que tu vives! » C'était en effet à l'intérieur de la science occidentale, de son savoir et de ses pratiques discursives qu'il fallait se situer pour construire un savoir et un discours efficaces sur l'Afrique. Pour dire les choses autrement, l'invention d'un discours africain procédait de la «cannibalisation » systématique du savoir occidental.

À une échelle moins grande, de nombreux articles de la revue Présence Africaine qui parurent dix ans après sa création (entre 1955 et 1957) témoignent largement de la pertinence de cette vaste entreprise. Un article consacré à la République léboue (Sylla 1955) présente toutes les caractéristiques de la rhétorique à l'œuvre dans les nouveaux récits historiques africains. Tout d'abord le plaidoyer. Assane Sylla remarque que cette «république» établie entre 1795 et 1857 était dotée d'une Constitution solide. Son destin ne devait rien aux «républiquessœurs » d'Europe occidentale au lendemain de la Révolution française, à laquelle elle ressemblait pourtant sur plusieurs plans. L'édification d'une société nouvelle, l'organisation d'une administration remarquable, la pureté de mœurs qui favorisait l'équilibre social, le respect des accords internationaux et des traités qui la distingue des mœurs diplomatiques des Européens, en faisaient un État parfait. Puis vient la critique. Il accuse les colonialistes d'avoir «assassiné » cette jeune république en 1857, «après avoir pleinement bénéficié de la largesse d'esprit de ses concitoyens ». Cela prouvait assez, selon lui, que «la civilisation noire n'était pas niable » et " qu'une petite République africaine avait pu naître et prendre conscience de sa force morale" (ibid. : 47). On sera sensible au vocabulaire utilisé dans les deux parties de l'argumentation : l'hagiographie des États africains dans la première, l'acte d'accusation de l'Europe occidentale dans l'autre. La nécessité de donner un corps et une valeur au discours, de faire entendre une autre voix dans cette liberté nouvelle retrouvée ou chèrement acquise justifiait sans doute la passion mise à réinventer cette histoire et à la faire entendre avec des accents de justicier. 
L'appropriation ou la réappropriation de l'histoire empruntaient chez Cheikh Anta Diop des accents politiques évidents, plus prononcés peut-être que chez de nombreux intellectuels africains de sa génération. Pour lui, la construction d'un discours de l'intérieur était une impérieuse nécessité et prenait parfois la forme d'une injonction. Il estimait, en tout cas, que l'histoire de l'Afrique noire resterait suspendue comme en l'air tant qu'elle ne serait pas écrite correctement par des historiens africains qui auraient consenti à la rapprocher de l'histoire de l'Égypte. Ce discours programmatique - rapprocher l'Afrique noire de l'Égypte - devait servir de base aux travaux d'histoire et d'anthropologie qu'il allait conduire tout au long des années et qu'il publierait là encore pour l'essentiel à Présence Africaine. Dans son non moins célèbre Antériorité des civilisations nègres, mythe ou vérité historique? (C. A. Diop 1967), où il entendait répondre à ceux qui doutaient en Occident et ailleurs de ses thèses et de ses vues, Cheikh Anta Diop plaidait pour un retour serein à la vérité historique et pour une logique de la construction des discours de savoir qui dégagerait toutes les conclusions évidentes de leurs prémisses. Ce savoir, par cette logique même, invitait à sortir du déni, à resituer l'origine du monde en Afrique, et à restituer celle-ci dans sa fonction de civilisation, primordiale, initiale et primaire. L'enjeu était bien sûr la reconnaissance de la place du Nègre dans l'histoire de l'humanité - vérité historique oblige! Mais il était aussi de fournir les moyens concrets de la défense ou de l'affirmation d'une conscience nègre au risque de sombrer dans l'essentialisme. La traduction de cet ouvrage en anglais, quelques années seulement après sa parution française (C. A. Diop 1974), allait installer son auteur et sa maison d'édition ainsi que les idées qu'ils portaient l'un et l'autre dans le champ d'un savoir scientifique naissant outre-Atlantique : les Africana Studies.

En se posant comme espace privilégié de la production d'un discours de savoir, Présence Africaine devenait le seul lieu où un savoir nègre pouvait s'épanouir librement sans le risque de l'étouffement. La revue et la maison d'édition allaient être les lieux de construction d'une science africaniste africaine, l'égyptologie, qui trouvait ici une force de conviction qu'aucune autre maison d'édition ni revue ne pouvaient lui offrir. L'aventure scientifique de Cheikh Anta Diop, ses thèses, seraient pour longtemps confondues avec Présence Africaine. Plus exactement, comme le montre encore aujourd'hui le nombre d'articles soumis à la rédaction de la revue, Présence Africaine est devenue la vitrine de ces thèses. Elle allait accueillir en leur donnant une audience internationale les premiers historiens professionnels africains.

À la différence d'un Cheikh Anta Diop, attaché surtout à la question de la vérité historique, ces professionnels de l'histoire se souciaient de la méthode classique de l'histoire et de son récit. Constatant à juste titre, dans une de ses premières contributions à la revue Présence Africaine, que «l'histoire est la mémoire des nations », Joseph Ki-Zerbo relevait ainsi "qu'il était de la plus haute importance pour la personnalité d'un peuple de cultiver cette mémoire collective ou, au contraire, d'en laisser oblitérer les trésors. Ainsi, le fait de reprendre conscience de son histoire est un signe de renaissance pour son peuple» (Ki-Zerbo 1957: 53). Si l'enjeu ici clairement défini était bien celui de la reconnaissance et de l'affirmation d'une identité nègre, le jeu portait surtout sur la formation du discours et sur la transmission du savoir.

En effet, la nouveauté du discours ne visait pas seulement - même si cela n'était déjà pas négligeable - à la prise de conscience par le Nègre de son histoire. Elle consistait à faire entrer un autre discours de savoir dans le champ de la disci- 


\section{LES CONDITIONS NOIRES : UNE GÉNÉALOGIE DES DISCOURS}

pline considérée avec ses usages. Les historiens africains allaient combiner leur passion pour l'Afrique à la passion pour l'histoire ou pour l'historiographie, sans que jamais l'une cède le pas à l'autre. Ils devaient aussi, malgré les nuances différentes de leurs discours, faire corps, c'est-à-dire ici faire chorus, afin de montrer une unité de l'Afrique.

La fable qui se dégage de cette reconstitution scientifique est assez simple. Suivant le découpage de l'histoire par périodes (de la préhistoire aux temps présents), des historiens comme Ki-Zerbo racontent l'histoire de l'Afrique en inversant le regard cognitif. Comme sur une tapisserie, celle-ci se déroule de la "préhistoire africaine" au "réveil de l'Afrique noire». On y découvre alors son Antiquité, son Moyen Âge avec l'expansion arabe, ses royaumes et ses grands empires, l'ébranlement de ces empires et les siècles de réajustement $\left(\mathrm{XVI}^{\mathrm{e}}\right.$-XIX $\left.\mathrm{X}^{\mathrm{e}}\right)$, les tentatives de réintégration $\left(\mathrm{xIx}^{\mathrm{e}}\right)$, l'invasion du continent et l'âge d'or des étrangers $\left(\mathrm{xIX}^{\mathrm{e}}-\mathrm{x} \mathrm{x}^{\mathrm{e}}\right)$, son indépendance, son poids économique, la valeur de ses cultures et de ses civilisations $\left(\mathrm{xx}^{\mathrm{e}}\right)$. La linéarité des récits, le nombre, la nature et la fonction des personnages historiques (Samori, Ranavalona par exemple), la diversité des sources convoquées illustrent l'étendue des savoirs qu'il faut mobiliser pour écrire l'histoire de l'Afrique noire. Une telle narration ouvre une double perspective : réintroduire l'histoire de l'Afrique dans l'histoire mondiale; réintroduire en retour l'histoire des mondes dans l'histoire africaine. Elle vise encore, sur le plan méthodologique, à prendre l'Afrique noire pour un seul et même espace historique. On doit ainsi à Joseph Ki-Zerbo et aux autres historiens africains (Baba Kaké, Tamsir Niane et plus tard M'Bokolo) d'avoir compris la nécessité de faire des recherches poussées et convaincantes sur ce passé que l'on disait «enfoui " afin de le révéler au monde et d'abord aux Africains eux-mêmes, en s'appuyant toujours sur la méthode historiographique héritée des maitres européens. Il s'agissait pour eux, comme le soulignera d'ailleurs plus tard Fernand Braudel dans sa préface à Histoire de l'Afrique noire, de «tenter de saisir dans son immensité et son obscurité obstinée le passé multiple, décevant, inorganisé et sans fin à recréer de l'Afrique noire " (Ki-Zerbo 1978 : 5).

L'enjeu scientifique bien perçu par Braudel ici avait déjà fait l'objet d'une mise au point chez Alioune Diop dans son célèbre «Niam n'goura ou les raisons d'être de Présence Africaine». Publier «des études d'Africanistes sur la culture et la civilisation africaines" (A. Diop 1947 : 7), comme il l'écrivait alors, supposait de prendre toute la mesure de la méthode scientifique qu'impliquait l'invention des récits. Cela supposait d'abord de faire de la revue non pas une revue d'Africains, mais bien une revue de scientifiques sur l'Afrique, c'est-à-dire de ceux pour qui la vérité sur l'Afrique comptait plus que toute idéologie; de ceux par qui pourrait s'édifier une relation de ce continent, de ses peuples et de ses diasporas : une relation, c'est-à-dire tout à la fois le récit par les Africains de leur propre vécu et les modalités de leur rapport au monde. Cela supposait surtout, et bien plus encore, sur le plan du récit historique qui nous intéresse ici, tout à la fois de dépasser "l'histoire des récits traditionnels " et de donner à ceux-ci une "place honorable et claire»- pour parler comme Braudel dans sa préface; une place susceptible alors de faire de la société africaine, de l'économie ou de la culture de grands sujets d'histoire.

Sur ce plan de la méthode, sans doute l'un des plus précieux, inventer l'histoire va consister d'abord à faire admettre que les formes de l'histoire africaine peuvent être parfois radicalement différentes de celles qui fondent cette science chez les historiens occidentaux; que les questions des "sources écrites", de la chrono- 
nouvelle série bimestrielle

$\mathrm{N}^{\circ}$ Spécial

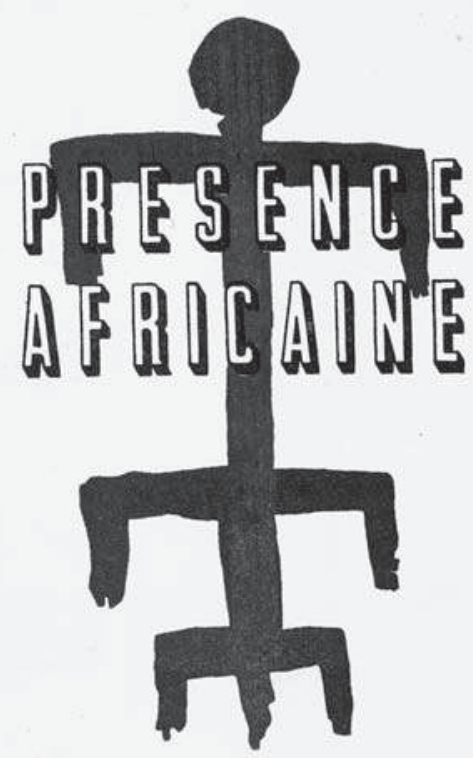

Le I ler Congrès International des Écrivains et Artistes Noirs

(Paris - Sorbonne - 19-22 Septembre 1956)

COMPTE RENDU COMPLET
Fig. 5 Compte-rendu du Premier Congrès international des écrivains et artistes noirs à Paris, septembre 1966 ㄷ Présence Africaine.

logie, de la tradition orale, de l'archéologie, de la linguistique, de l'anthropologie, de l'ethnologie, des autres arts et sciences devaient être repensées en vue d'une approche générale du dire historique. Les chantiers conduits ne laisseront alors en plan aucun des pans de la pensée et du savoir. L'historien africain devra ainsi épouser plusieurs manières de faire, être constamment à l'affût des innovations scientifiques dans tous les domaines du savoir. Sa tâche sera la «recréation d'un humanisme à la vraie mesure de l'homme", disait Alioune Diop dans «Niam n'goura » (ibid.); formule à laquelle fera écho celle de Joseph Ki-Zerbo dans sa définition de l'histoire : «L'histoire est une science humaine qui est à la recherche d'un certain degré de certitude dite morale ou de probabilité qui lui permet de restituer et d'expliquer le passé de l'homme " (Ki-Zerbo 1957 : 27). Il fallait donc inventer une histoire générale de l'Afrique, c'est-à-dire, à partir de nombreuses histoires particulières, recréer une histoire «globale » du (et à partir du) continent. 


\section{LES CONDITIONS NOIRES : UNE GÉNÉALOGIE DES DISCOURS}

L'attention portée aux différentes disciplines sera favorisée par le cadre scientifique français dans lequel s'insère l'entreprise de l'historien africain; un cadre scientifique des années 1950 propice à une recomposition du paysage scientifique, comme l'avait remarqué Alioune Diop et comme le suggérera à son tour KiZerbo. Celui-ci remarquait précisément que «l'historiographie africaine entre en scène à un moment où une révolution s'opère dans la conception générale de l'Histoire [...] L'histoire veut embrasser en largeur et en profondeur le fleuve de l'évolution humaine» (ibid. : 16). Ce cadre, bien maîtrisé, permet aussi de noter que l'historiographie africaine, du point de vue des récits tout au moins, aura été le lieu d'une constante modernité, d'une singulière actualité, d'un attachement aux évolutions théoriques et techniques de la discipline. À la différence d'un Cheikh Anta Diop, pour qui l'enjeu scientifique était, au besoin, d'organiser une science proprement africaine, d'inventer une discipline, l'égyptologie africaine, comme on l'a déjà dit, l'enjeu pour les historiens africains de cette nouvelle narration historique était, et de loin, de pédagogie et de transmission. Le souci de Ki-Zerbo était d'écrire des livres d'histoire pour l'enseignement. En ce sens, il partageait avec Alioune Diop le souci de l'avenir, de la construction d'un espace de savoir propice à l'émergence d'une conscience de soi plus grande des Africains. L'ouvrage de Ki-Zerbo Histoire de l'Afrique est une synthèse magistrale de travaux d'historiens publiés pour la plupart par Présence Africaine. Outre la participation active de cette dernière à la publication en édition abrégée de l'Histoire générale de l'Afrique ${ }^{2}$, on remarquera dès la fin des années 1960 une production régulière de travaux sérieux d'historiens africains qui vont marquer les esprits et baliser les contours du discours scientifique durant une triple décennie (1970-1990). On peut citer, entre autres, Documents d'histoire de l'Ouest africain pour l'enseignement secondaire. Le Moyen Âge: $\mathrm{VII}^{e}$-XVI ${ }^{e}$ siècles (Cissoko 1965) ou Histoire de l'Afrique occidentale. Moyen Âge et temps modernes, vII siècle - 1850 (Cissoko 1966), Histoire de l'Afrique (Dione et Cissoko 1973), Le Soudan occidental au temps des grands empires (XI ${ }^{e}-\mathrm{XVI}^{\mathrm{e}}$ siècles) (Tamsir Niane 1975), Glossaire critique des expressions géographiques concernant le pays des Noirs, d'après les sources de langue arabe (Baba Kaké 1971), Histoire de l'Afrique centrale à l'usage des lycées et collèges (Baba Kaké et al. 1971), Les Sources de l'histoire négro-africaine depuis Homère jusqu'à Strabon (Mveng 1972), Histoire de Gobir et de Sekoto (Boubou 1967) ou Éveil du nationalisme. L'Est africain aux XIXe et Xx siècles (M'Bokolo 1990). Cette énumération montre la vertu de l'accumulation des discours dans la pratique de l'activité des historiens africains.

La modernité, l'actualité de l'histoire seront les moyens de reparcourir tous les sujets qui permettent de rendre compte de l'humanité des Nègres. À côté des sujets de la reconstitution des empires précoloniaux, de la relation des histoires coloniales, l'histoire de la traite et de l'esclavage va occuper une place importante dans l'élaboration des récits africains que donne à lire Présence Africaine. Outre les travaux consacrés à la crise du sucre aux Antilles et aux conditions de navigation des Africains à bord des bateaux négriers, une attention doit être accordée à tous ces récits produits sur la situation économique et politique des îles et sur les conséquences néfastes de l'esclavage pour les sociétés africaines et antillaises. Toussaint Louverture : la Révolution et le problème colonial d'Aimé Césaire (Césaire 1962) est une des analyses les plus perspicaces consacrées à la question de l'esclavage durant la période coloniale. Au-delà du rappel d'un épisode qui n'est pas absent de l'historiographie française, comme on peut le voir à travers la littérature du xix $x^{e}$ siècle - chez un Lamartine par exemple ${ }^{3}$-, et au-delà 
de la singulière réappropriation de la mémoire, c'est la qualité du récit et sa portée qui doivent retenir l'attention ici. En effet, Césaire fait comprendre l'histoire d'Haïti et celle de Toussaint Louverture par rapport à l'histoire de la France révolutionnaire de son époque. Il montre combien les esclaves d'Haïti, en créant la première république noire du monde, ont conduit jusqu'à leur stade ultime les conséquences de la Révolution française, rendant celle-ci suffisamment universelle pour pouvoir s'imposer en définitive à tous les peuples. Pour Césaire, c'est Toussaint qui donne une figure humaine et son sens à la Révolution.

Cet ouvrage servira de prétexte à la création d'une collection, "Situations et perspectives", qui, dès 1967, réunit les travaux qui doivent interroger la réalité économique (Williams 1968), les mentalités (Hazoumé 1972) et, plus tard, le développement de la religion en Afrique - et particulièrement la religion chrétienne - (Eboussi-Boulaga 1981), ou, plus largement, les rapports entre science et vie (Mudimbé 1982). Il s'agissait de suivre dans leur cours les préoccupations des sociétés et des peuples africains dans la période postcoloniale et sous les soleils des indépendances.

\section{L'invention de la littérature}

On ne sera pas surpris que, dans cette volonté d'écrire une histoire de l'Afrique, une attention soit accordée à la littérature. Dans le double "numéro spécial " (89) de la revue Présence Africaine (1950), qui, sous la direction de Théodore Monod, entendait réhabiliter l'image du Noir, une troisième partie, intitulée «Derrière la façade ", recensait tous les arts, dont la littérature, la musique et la danse. On le sera d'autant moins lorsqu'on comprendra que, dans le combat qu'il fallait mener en vue de faire admettre l'existence d'un être nègre, dans un environnement toujours hostile et avec des méthodes facilement contestables, c'est à travers la fiction que l'histoire africaine pouvait réellement être écrite. Comme l'histoire, elle a été aussi le lieu de la recherche d'une identité discursive. La querelle qui va opposer Alexandre Biyidi (le futur Mongo Beti) à Camara Laye, ou plus exactement la critique féroce que le premier fera des romans du second dans les colonnes de la revue Présence Africaine, en témoigne largement. Après avoir qualifié L'Enfant noir (1954) de " roman à l'eau de rose », dans lequel aucune situation coloniale n'est décrite, Biyidi va montrer, lors de la publication du Regard du roi, combien Laye ressemble plus qu'il ne veut le croire à ce jeune roi qu'il met en scène dans le roman: "soumis au rôle qu'il doit jouer, insaisissable, et somme toute d'assez peu de jugement puisqu'il ne semble guère s'occuper des affaires du monde. Comme son roi, sous les oripeaux chatoyants du beau style, et les lourdes fibules conventionnelles, Camara Laye laisse apercevoir une constitution maigrichonne ». Ce nouveau roman a baissé d'un cran sur l'échelle de la vraisemblance par rapport à L'Enfant noir, qui était déjà une entreprise de mystification. Pour Biyidi, l'œuvre de Laye «ne pourra jamais trouver place qu'au rayon de la littérature noire» (Biyidi 1955 : 133-145). Le jeu de mots ici est appréciable. La littérature noire, faite de pittoresque, de descriptions gratuites, de dialogues insipides, ne constituera jamais une partie de la littérature des Noirs. Une littérature nègre plaisante et rassurante pour le public européen, produite par des clercs dociles et ambigus, est une littérature qui «n'apportera vraiment rien de neuf » et ne servira pas de modèle à la production du discours efficace dont le peuple noir a besoin. Comme un «cabinet noir », il faudrait donc s'en méfier... 


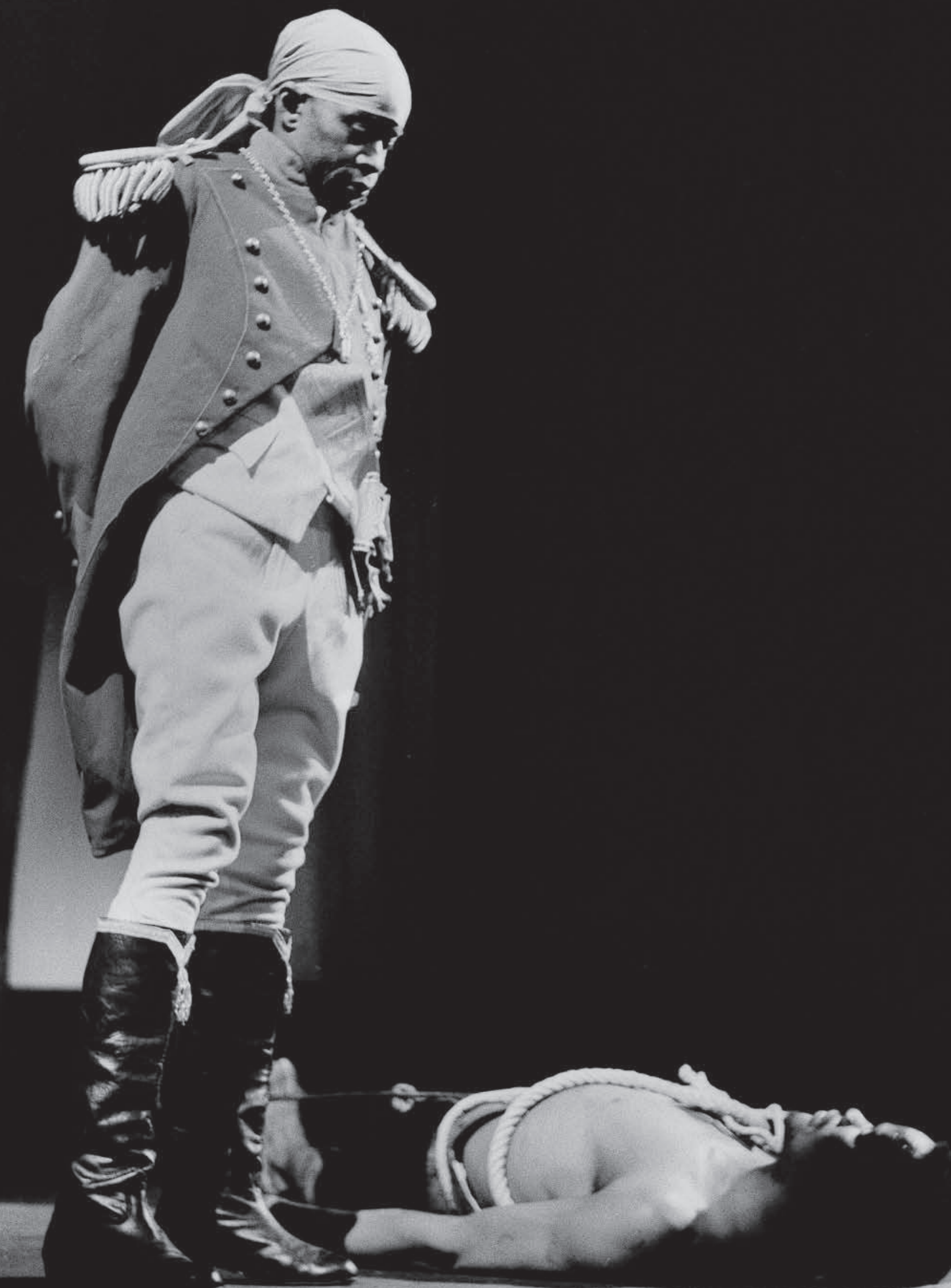


Aimé Césaire et René Depestre vont s'opposer sur un sujet semblable : la nature et les limites d'une poésie nationale. Dans une lettre à Charles Dobzynski envoyée depuis le Brésil et publiée dans la revue Les Lettres françaises, Depestre s'était interrogé sur l'adéquation entre le fond et la forme du poème et s'était prononcé pour le vers français, suivant ainsi la voie préconisée par Louis Aragon. Aimé Césaire va s'insurger, à la manière d'un Alexandre Biyidi (Mongo Beti), contre Camara Laye, contre cette conception de la poésie. Dans sa «Réponse à Depestre poète haïtien », sous-titrée «Éléments d'un art poétique (Césaire 1955), Césaire considère que toute révolution s'accommode mal d'une injonction qui ne relèverait pas d'elle : "Camarade Depestre / C'est un problème assurément très grave / des rapports de la poésie et de la révolution / le fond conditionne la forme / et si l'on s'avisait aussi du détour dialectique / par quoi la forme prenant sa revanche / comme un figuier maudit étouffe le poème / mais non / je ne me charge pas du rapport / j'aime mieux regarder le printemps. Justement / c'est la Révolution / et les formes qui s'attardent à nos oreilles bourdonnant / ce sont mangeant le neuf qui lève / mangeant les pousses / de gras hannetons hannetonnant le printemps. " Césaire se prononce ici pour la liberté poétique, celle par laquelle tout poète doit pouvoir accorder selon son seul vouloir le fond et la forme. Car, pour lui, «le poème n'est pas un moulin / à passer de la canne à sucre ça non / et si les rimes sont mouches sur les mares / sans rimes / toute une saison / loin des mares / moi te faisant raison / rions, buvons et marronnons ». La forme générale du poème ici usitée par Césaire montre assez que la question de la liberté poétique n'est pas liée à la forme ou, plus exactement, que la relation de la forme à son fond est une fausse question esthétique.

Au-delà du pamphlet, l'enjeu véritable est celui des limites de la littérature. L'un des aspects de la critique de Biyidi à Camara Laye portait sur l'identité de cette dernière. "Ce qui distinguera les romanciers africains, écrivait-il, c'est bien moins leurs origines ethniques que leurs différents tempéraments et personnalités. " L'exigence réaliste est la seule qui puisse permettre, selon lui, que s'édifie une «littérature africaine authentique». L'écrivain prenait ainsi le risque de ne pas se faire publier par les maisons d'édition «bourgeoises». «Les temps - en 1955 - ne sont pas propices pour une littérature africaine authentique : ou bien l'écrivain africain est réaliste, et [...] il ne risque pas d'être publié, mais même s'il y parvenait, la critique l'ignorerait, le public aussi. Ou bien il est conformiste et dans ce cas il risque de donner dans le pittoresque gratuit et même dans le fantastique» (Biyidi $1955:$ 139).

Senghor consacre lui aussi une partie de sa «contribution au débat sur la poésie nationale " (Senghor 1956 : 80) à la même question du "style de nos romanciers ", c'est-à-dire en définitive à l'identité de la littérature et donc à ses limites. Il partage - une fois n'est pas coutume - les vues d'Alexandre Biyidi sur le réalisme : «Faut-il lui apprendre [à Depestre] qu'il y a un réalisme négro-africain? et que son apport ne peut se limiter au seul rythme, qui, au demeurant, est déjà forme? Faut-il lui apprendre qu'il y a une imagerie négro-africaine, une rhétorique négro-africaine, c'est-à-dire un style, et que la tradition à assimiler-j'emploie un verbe actif - n'est pas que française? » À la différence d'un Biyidi, qui ne se pose pas la question de la qualité ou de la nature culturelle du réalisme, Senghor distingue le réalisme négro-africain de tous les autres réalismes. Si ces défenseurs et théoriciens proclament la méthode «objective parce que scientifique», le réalisme ne commande pas le roman. Au contraire! Sa seule force réside dans cette sorte de subjectivité par quoi se définit finalement toute œuvre d'art, une
Fig. 6 La Tragédie du roi Christophe, pièce d'Aimé Césaire mise en scène par JeanMarie Serreau au théâtre de l'Odéon à Paris en 1965 ; jouée par la Compagnie du Toucan qui rassemble des acteurs sénégalais, antillais et Haïtien. ○) Studio Lipnitzki / Roger-Viollet 
subjectivité qui est inscrite au cœur même de l'œuvre et lui est consubstantielle. Il invite alors les écrivains à procéder à la manière de Richard Wright, dont JeanPaul Sartre pensait qu'il compromet le lecteur par son lyrisme. Pour faire sentir la situation du Nègre, il procède «non pas objectivement à la manière des réalistes, mais passionnément et de manière à compromettre son lecteur ». Produire un discours neuf pouvait relever d'un acte passionné, comme le pensait Senghor, ou exiger, comme l'estimait Biyidi, de la personnalité ou du tempérament. L'entreprise littéraire supposait tout à la fois la reconnaissance d'une liberté d'écriture et l'existence d'une intention - pour parler comme Glissant (Glissant 1969).

Jacques-Stephen Alexis, l'écrivain haïtien, allait mettre tout le monde d'accord en revenant sur la nature du roman. Présence Africaine avait ouvert un «Débat autour des conditions d'un roman national chez les peuples noirs» dans le but de mettre en lumière, comme le précisait Alioune Diop, trois «thèmes principaux»: l'authenticité du message africain ("populaire»); "l'accent revendicatif » inhérent à la situation du colonisé; le " public » auquel est (doit être) destinée l'œuvre. Dans sa contribution intitulée "Où va le roman? ", Alexis, en marxiste convaincu, liait la production du roman à l'évolution sociale. Pour lui, on ne pouvait séparer le combat pour une littérature nationale des conditions nationales d'accession des populations au savoir et à la connaissance par l'éducation et l'instruction publique. "La maturité romanesque d'un peuple ne s'exprime par des romans répondant à la définition actuelle que dans la mesure où la culture de ce peuple franchit le stade d'une littérature parlée, verbale, orale, pour atteindre celui d'une littérature écrite. » Il affirmait aussi sa conviction que, "par un réalisme combattant, un réalisme lié à notre sol, à la création populaire de chez nous, comme à tout l'acquis progressiste de l'univers, nous sommes en mesure de produire, dans le roman comme dans plusieurs autres disciplines, quelque chose de vraiment neuf. Bien plus, il est même loisible de penser qu'avec les trésors de leurs formes culturelles jusqu'ici inemployées dans l'art professionnel, les peuples noirs et sous-développées sont aujourd'hui en mesure d'enlever pour un bout de temps l'initiative à l'Occident dans le rajeunissement et la découverte de formes artistiques nouvelles, éclairant ainsi le destin de l'art pour toute l'humanité " (Alexis $1957: 83$ ).

Qu'il s'agisse donc de prolonger le réalisme ou de l'adapter à la situation des peuples noirs (Biyidi et Alexis), ou, au contraire, de défendre le lyrisme (Senghor), tous ces auteurs étaient convaincus, avec Alioune Diop, qu'il fallait accorder une place à la littérature dont le style seul pouvait donner aux peuples noirs une identité certaine. Comme dans le domaine de la science historique, la prise de parole était le but ultime des auteurs nègres. Comme pour la science, la quantité de textes produits (accumulation de romans, nouvelles, poèmes, pièces de théâtre, etc.) était nécessaire. L'exigence de qualité de ces discours littéraires devait occuper une place plus importante encore. Suivant une conception très française qui accorde depuis la naissance des intellectuels un intérêt aux dires des clercs (hommes de lettres et écrivains) dont on peut trouver encore plusieurs exemples dans de nombreuses revues parisiennes (Les Temps modernes, Esprit, la Revue des deux Mondes) et françaises de l'étranger (Voici ou Les Lettres françaises) durant la guerre, Présence Africaine va dessiner en creux le portrait de l'écrivain et déterminer les limites de sa littérature.

On pouvait déjà constater, à travers la polémique qui opposait Depestre à Césaire ainsi qu'aux autres poètes nègres, et à partir de la critique d'Alexandre Biyidi à Camara Laye, les caractères de ce nouveau discours littéraire africain. Un 
survol rapide de la production romanesque de Présence Africaine entre le milieu des années 1950 et la fin des années 1980 permet de montrer que son fondateur, Alioune Diop, a mis au service de la création d'une identité littéraire africaine toutes ses connaissances de l'histoire et de la vie littéraire françaises. Pour lui, l'identité littéraire d'un peuple passait, d'une certaine manière, par la création de classiques. Il fallait faire surgir dans le champ littéraire (européen et africain) des auteurs qui, selon l'expression de Sainte-Beuve dès 1850, enrichiraient «l'esprit humain ", augmenteraient «le trésor » de l'humanité (et de la langue française), auraient «fait un pas de plus, rendu par leurs pensées, leurs observations ou leurs inventions sous une forme n'importe laquelle, mais large et grande, fine et sensée, saine et belle en soi ». Il fallait publier des œuvres qui parleraient chacune «à tous dans le style particulier " de leurs auteurs, "qui se trouverait aussi [être] celui de tout le monde".

Cette idée de l'invention des classiques se dégage des trois principes qui doivent caractériser le roman africain. Le premier est son "authenticité " ou sa dimension "populaire». En confondant ces deux termes, Alioune Diop pense que le point commun de toutes les nouvelles œuvres africaines doit être de présenter "une histoire selon une chronologie simple avec des personnages bien identifiés, et où l'intrigue ou l'action primerait sur les considérations de style". La méfiance générale suscitée par la position doctrinale d'un Depestre aidant, il devait porter à la question du contenu des œuvres un soin particulier. Le mot "populaire " pouvait cacher l'ambition de donner à cette littérature africaine des œuvres aussi valables que celles d'un Maurice Leblanc, d'un Gaston Leroux ou d'un Alexandre Dumas. En réalité, il fallait y voir la volonté de ne pas couper la nouvelle littérature africaine écrite dans les langues européennes (ici, le français) des littératures orales anciennes et traditionnelles.

Le second principe concerne la «revendication» ou, plus exactement, ce que l'on pourrait appeler son "engagement ». L'œuvre littéraire africaine ne saurait être neutre. La notion de réalisme débattue aussi bien par Alexis, Biyidi que Senghor trouvait ici sa justification pleine et entière. L'œuvre devait prendre en compte la réalité telle qu'elle est et en rendre compte avec le tempérament utile à sa portée. Défendre les libertés individuelles et collectives, rendre compte de la «situation" sans complaisance, voilà quelques mots d'ordre de cette invention esthétique.

Ces aspects devaient sans doute conduire le troisième et dernier principe : l'invention d'un public. On comprendra alors qu'une certaine dimension pédagogique n'était pas absente des vues d'Alioune Diop. Une identité littéraire n'avait de chance que dans la mesure où les masses populaires seraient éduquées afin d'accéder à un niveau de culture qui rendrait évidente leur participation au jeu social de la littérature. Produire des œuvres à lire par un public d'avertis dont l'accroissement était nécessaire au maintien de l'entreprise de création artistique, tel était le défi qu'imposait la recherche permanente de public(s). Sans un public captif et convaincu de la nécessité de la lecture, aucune entreprise de création littéraire n'était viable.

De fait, une politique de l'édition devait suivre ces trois principes simples, mais clairs et efficaces, avec un savant dosage entre la production éditoriale et la publication de la revue. Le premier roman de Mongo Beti, publié sous le pseudonyme d'Eza Boto, Ville cruelle, portait déjà en germe tous les éléments de cette théorie. Sorti un an seulement après L'Enfant noir, il se voulait son exact contraire. Une chronique (contre l'autobiographie), une situation identifiable (la 


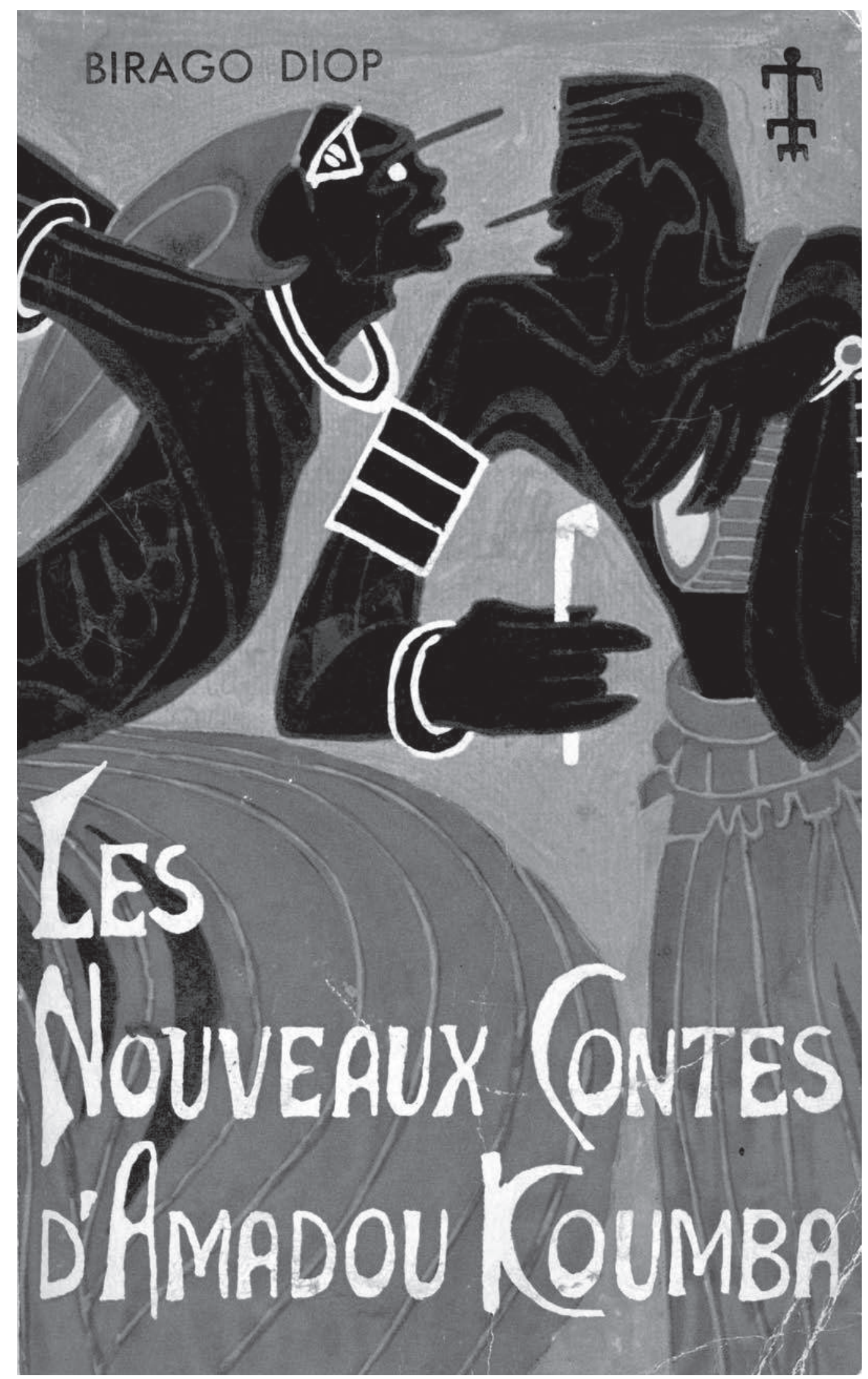

Fig. 7 Les Nouveaux contes d'Amadou Koumba de Birago Diop, 1958 ๑ Présence Africaine. 
situation coloniale contre l'Afrique paisible), des personnages repérables (des types contre des figures interchangeables), tels sont les aspects immédiats du récit. Loin de l'Afrique immémoriale de la Guinée, cette autre Afrique littéraire portait les empreintes de la colonisation.

Quelques années plus tard, Présence Africaine publiait dans un numéro de la revue $\left(\mathrm{n}^{\circ} 16,1955\right)$ intitulé "Trois écrivains noirs" un recueil réunissant Ville cruelle du camerounais Eza Boto, Cour d'Aryenne du congolais Jean Malonga, et Nini, mulâtresse du Sénégal d'Abdoulaye Sadji. Conçue visiblement comme une opération de marketing littéraire, cette publication avait pour but de montrer la diversité (géographique et esthétique) des auteurs de la maison d'édition, la variété des esthétiques, l'unité du discours anticolonial des œuvres. Ce nouveau discours romanesque était différent de celui des œuvres antérieures, qui soulevaient presque toutes le conflit entre la tradition et la modernité vécu par les Africains. Il suffit de rappeler les romans sénégalais bien connus, Karim d'Ousmane Socé (1935), Force-Bonté de Bakary Diallo (1920), Les Trois Volontés de Malic d'Ahmadou Mampate Diagne (1920), où les personnages évoquent les contraintes de leur appartenance aux deux cultures, française (moderne) et traditionnelle (musulmane). Il suffit encore de rappeler Doguicimi du béninois Paul Hazoumé (1938) ou L'Esclave du togolais Félix Couchoro (1920), qui s'intéressent à l'histoire du règne de Gezo (Hazoumé) ou à la pratique de l'esclavage dans l'ancien Dahomey (Couchoro).

L'opération de marketing va ouvrir la voie à une intense production. Pour renforcer la dimension authentique et populaire dont on a parlé plus haut et montrer que la littérature en langue européenne pouvait s'accommoder du savoir africain, la maison d'édition devait accorder une importance au genre du conte. Le Pagne noir, contes africains de Bernard Dadié, publié dès $1955^{4}$, a connu un succès de librairie d'autant plus mérité qu'il allait rapidement servir d'outil pédagogique pour les classes des écoles de l'Afrique indépendante naissante. La simplicité des récits, l'évidence de la morale, la réalité des personnages font de ce recueil de contes un ensemble qui ne tarda pas à imposer ce genre comme l'une des marques de fabrique de la littérature négro-africaine. Une collection fut même créée en vue de donner à lire les contes du "monde noir", africain et antillais. On ne peut s'empêcher de relever l'effet de série dans les titres qui suivent. Après les célèbres Contes d'Amadou Coumba (1958), Contes et lavanes (1963) et Nouveaux contes d'Amadou Coumba (1967) de Birago Diop, viendront À la belle étoile, contes et nouvelles d'Afrique de Benjamin Matip (1962), Les Contes gabonais d'André Raponda-Walker (1967), Les Contes et légendes du Niger de Boubou Hama (1972-1973), Les Contes d'hier et d'aujourd'hui de Djibril Tamsir Niane (1972), puis les Contes créoles de Jean Juraver (1982) ou Les Contes de Koussou-as-Samala de Bernard Dadié (1982). Plus d'une cinquantaine de titres publiés entre 1958 et 1988 confirmeront l'intérêt de retrouver dans chaque nation les discours du terroir. Ces textes creusaient le sillon d'un humanisme de l'Afrique, comme l'avait fort bien remarqué Roland Colin (Colin 1957).

Le théâtre occupera une place tout aussi remarquée. Une collection créée elle aussi en 1972 accueillera jusqu'à 1990 environ une vingtaine de titres. On y retrouve des figures devenues des classiques du genre, comme Aimé Césaire (Et les chiens se taisaient. Tragédie, 1974), Bernard-Belin Dadié (Monsieur Thôgôgnini, 1970, 1990), Tchicaya U’Tamsi (Le Destin du maréchal Nnikon Nniku, 1979), Jacques Rabemananjara (Les Dieux malgaches, 1988), Wole Soyinka (La Métamorphose de Frère Jéro, 1986) ou Félix Morisseau-Leroy (L'Antigone créole, repris au de 1979, a été tirée à plus de 20000 exemplaires. 
Théâtre des Nations à Paris). Ces pièces s'écrivaient en même temps que la scène française-singulièrement parisienne-découvrait et montait des auteurs nègres (Césaire et Morisseau-Leroy) et qu'en Afrique se créaient des troupes de théâtre professionnelles. Comme pour le conte, la dimension didactique et pédagogique du théâtre n'était pas absente de l'esprit d'Alioune Diop. Dès 1958, il avait publié l'essai de Bakary Traoré Le Théâtre africain et sa fonction sociale, qui montrait la théâtralisation de la société africaine et la socialisation du théâtre en Afrique, son rôle rituel, sa fonction esthétique et pédagogique (Traoré 1958). Cette étude devait servir longtemps de discours de la méthode des analyses et des enquêtes consacrées au théâtre africain.

Le roman négro-africain moderne, de facture populaire et à caractère authentique, est de tous les genres considérés ici celui auquel Alioune Diop accorda le plus d'attention. Les différentes œuvres publiées plus tard devaient obéir en gros à tous ces critères. Parmi les auteurs considérés comme classiques négroafricains, on comptera tous ceux qui, à des degrés divers, dénoncent la colonisation et ses avatars historiques en Afrique (le néocolonialisme et les dictatures, la déshumanisation de l'homme, la fuite en exil). En 1972, une collection intitulée sobrement «Écrits » va réunir plusieurs de ces titres et donner plus de visibilité à cette littérature. On n'y compte pas moins de cinquante-cinq titres publiés entre 1972 et 1989, dont Le Cercle des Tropiques du guinéen Alioum Fantouré (1972), qui inaugurait la collection. Celle-ci réunissait des auteurs connus : Bernard Dadié (Un nègre à Paris, 1976), Sembène Ousmane (Voltaïque, la noire de, 1962, 1971) ou Mongo Beti (Le Pauvre Christ de Bomba, 1976); des nouveaux venus, Williams Sassine (Saint Monsieur Baly, 1973), Bertène Juminer (Les Bâtards, 1978), Henri Lopès (Le Pleurer-rire, 1982), Sylvain Bemba (Le Soleil est parti à M'Pemba, 1982), V. Y. Mudimbé (Entre les eaux, 1973) ou Pape Pathé Diop (La Poubelle, 1984). Cette génération va précéder l'actuelle, celle de Mabanckou et de Fatou Diome, de Daniel Biyaoula et de Ken Bugul, de Véronique Tadjo et de Jean-Roger Essomba, qui, depuis la fin des années 1980, renouvelle à des degrés divers cette thématique de la revendication et de la dénonciation.

Deux points qui soulignent l'importance de cette notion de classique méritent toutefois d'être évoqués. Le premier est l'intrusion dans l'espace de la littérature des écrits de femmes. En 1985, Aminata Maïga Ka publie ainsi dans cette même collection «Écrits » La Voie du salut, suivi du Miroir de la vie. L’auteur y raconte le caractère dérisoire de la puissance de la femme «initiée au monde des affaires et de la politique». Ici, la critique porte sur l'attitude des nouvelles générations de femmes africaines, fascinées par la domination et qui reproduisent le modèle honni des pesanteurs sociales rétrogrades. Les manifestations de pouvoir sont toujours folkloriques. Le second concerne la fortune de cette conception de la littérature négro-africaine. Elle est familière aujourd'hui parce qu'elle a désormais franchi le cadre des seules productions de la maison d'édition. En effet, des auteurs africains comme Ahmadou Kourouma (Les Soleils des indépendances, 1968-1970), Sony Labou-Tansi (La Vie et demie, 1979) ou Tierno Monenembo (Les Crapauds-brousse, 1979), qui publient leurs textes aux éditions du Seuil, ne se conforment pas moins par leurs discours littéraires à ces mêmes critères esthétiques et théoriques.

Après la formation des classiques, l'exposition des chefs-d'œuvre. Pour intéressante qu'elle fût, la notion de classique de la littérature négro-africaine risquait d'enfermer cette dernière dans un espace exclusivement français. Pour sortir de ce piège et retrouver le monde noir qui l'avait portée, Présence Africaine va se 
donner pour mission de traduire en français les textes les plus importants des Noirs ou des littératures noires produites dans d'autres langues, de montrer qu'il existe partout dans ce monde noir des chefs-d'œuvre : des œuvres accomplies, parfaites, immortelles ou universelles qui appartiennent ou méritent d'appartenir au patrimoine de l'humanité. L'un des premiers textes traduits en français est Âmes noires de W. E. B. Du Bois (1959). Cet ouvrage, The Souls of Black Folk, paru en 1903, avait déjà connu outre-Atlantique vingt-cinq éditions et ne pouvait toujours pas être lu dans les communautés de langue française (à Paris ou ailleurs). L'auteur apporte à la vision de la littérature adoptée par Diop un complément singulier. Il soutient en effet que l'émancipation des peuples noirs aux ÉtatsUnis ne peut se faire sans le rôle joué par leurs leaders. La collection «Écrits " devait poursuivre cette tâche en mettant à la portée du public africain de langue française et du public européen nombre de textes d'auteurs du Commonwealth ou du monde lusitanien. Ainsi, par exemple, des œuvres de Chinua Achebe (Le monde s'effondre, 1972, ou La Flèche de Dieu, 1978), de Cyprian Ekwensi (La Brousse ardente. Histoire fulani du nord du Nigeria, 1978) et plus tard de Abéhikin Laurent Mama (Akoun : récit du Fokwé, 1980). Ainsi aussi du roman en langue portugaise de Vieira José Luandino (La Vraie Vie de Domingos Xavier, suivi de Complot de Mateus, 1971).

Cette politique de l'exposition du chef-d'œuvre ne concerne pas seulement les textes à traduire. Elle porte aussi sur la réédition de textes publiés en français dans d'autres maisons d'édition. Ce fut particulièrement le cas dans les années 1950 avec Zobel et Césaire. Le célèbre texte du premier, La Rue Cases-nègres, fut d'abord publié chez Froissart en 1950, puis aux Quatre-Jeudis en 1955, avant de connaître un succès de librairie incontestable en passant par Présence Africaine. Cette seconde jeunesse va en faire le best-seller que l'on sait, ainsi que le roman porté à l'écran de façon tout aussi remarquée. Le roman reste encore aujourd'hui un modèle pour les écrivains de la créolité, comme ont bien voulu le reconnaître aussi bien Patrick Chamoiseau que Raphaël Confiant. Le texte du second, Discours sur le colonialisme de Césaire, a connu un destin éditorial semblable. Publié par les éditions Réclame en 1950, ce pamphlet qui était en déshérence sera repris par Présence Africaine en 1955 avant de connaître avec le Congrès de 1956 une envolée méritée dont on peut suivre encore la puissance de la réflexion et la profondeur du propos dans la critique contemporaine. On ne dira rien du plus célèbre ouvrage de la maison, Cahier d'un retour au pays natal, publié dans l'édition définitive à Présence Africaine (1956), après bien des tribulations depuis sa première gestation dans la revue Volontés en 1939.

Ou'il s'agisse de l'écriture de l'histoire ou de l'invention de la littérature, Présence Africaine aura contribué par-dessus tout à faire entrer sur la scène de l'histoire - pour reprendre la formule de Césaire à la fin de son intervention au moment du Congrès de la Sorbonne de 1956 - les intellectuels nègres, africains et antillais. Cette contribution restera sans doute l'une des plus importantes du $\mathrm{xx}^{\mathrm{e}}$ siècle. Ceux-ci ont pu se forger une visibilité dans le champ des savoirs historiques et se faire une place dans le domaine de la littérature dont on mesure aujourd'hui peut-être la portée. De sorte que les critiques et historiens africains, et tous les intellectuels noirs, peuvent dire de la maison d'édition créée par Alioune Diop ce qu'ont affirmé les écrivains créoles d'Aimé Césaire : «Nous sommes tous désormais fils de la maison Présence Africaine. »

On le voit, il n'est guère de maison d'édition qui ne soit à ce point restée fidèle à ses engagements premiers. Présence Africaine, avec des fortunes diverses et 
face à la concurrence d'autres maisons d'édition, aux moyens considérablement supérieurs et profitant de réseaux de distribution autrement plus importants, a réussi à tenir le cap et ne s'est pas étiolée tout au long de ses soixante-deux années d'existence. Son désir de continuer à être le lieu d'une parole africaine non oublieuse de son identité demeure indéfectible. Les enjeux sont considérables : prisonnière de la mondialisation, convoitée pour ses richesses, chasse gardée de pays riches peu enclins à l'émanciper de leur tutelle, l'Afrique doit tous les jours, au travers de sa jeunesse, de ses politiques, de ses intellectuels, lutter pour advenir à une identité qu'elle seule est en droit de définir, sauf à n'être qu'une lointaine province de pays nantis. Pour cela, Présence Africaine, haut lieu de la culture africaine, doit continuer sur la voie que ses aînées ont tracée, publier les travaux des intellectuels annonciateurs d'un temps où sera reconnue dans sa pleine mesure la dimension civilisatrice des pensées africaines. Nul doute que des résistances continueront à faire obstacle, qu'il sera difficile de se faire entendre, que de faux honneurs cacheront de véritables dénis et que les portes de l'Occident ne s'ouvriront qu'avec parcimonie pour que puissent être entendues d'autres voix que celles que l'Occident a fabriquées au nom de l'image qu'il se fait de l'Afrique. Bref, autant de raisons pour penser que Présence Africaine a, comme au premier jour, toute sa place pour donner libre cours à une parole encore peu entendue.

Université de Strasbourg/Middlebury College School of French (USA) rfonkoua@middlebury.edu -

École Supérieure d'Arts Appliqués-Duperré marc.howlett@wanadoo.fr

mots clés / keywords : Alioune Diop // Alioune Diop • monde noir // Black world • philosophie africaine // African philosophy $\cdot$ égyptologie // egyptology $\cdot$ histoire africaine // African history $\cdot$ littérature noire // black literature $\cdot$ Revue Présence Africaine // Journal Présence Africaine •roman négro-africain // Negro-African novel $\bullet$ poésie nationale // national poetry $\cdot$ art africain // African art $•$ spiritualité africaine // African spirituality.

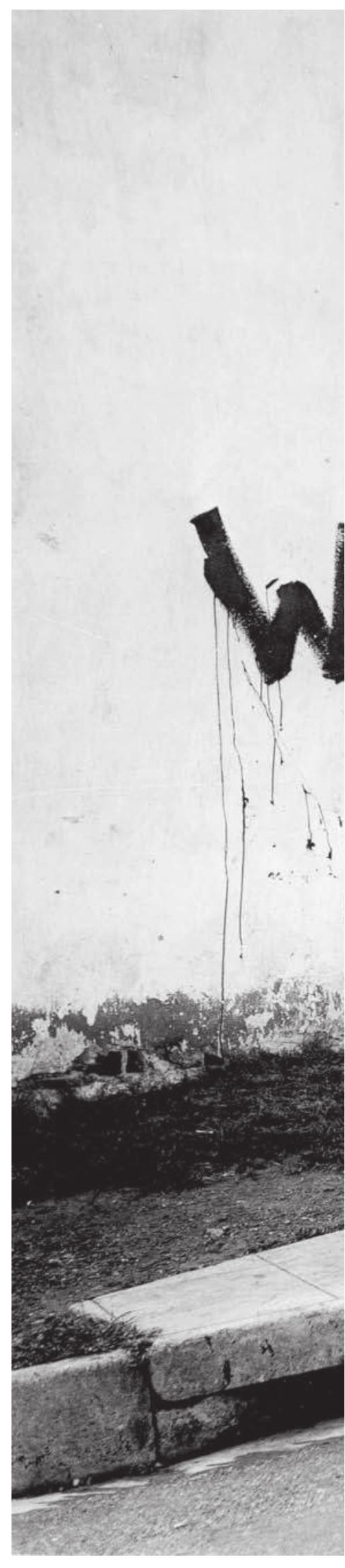



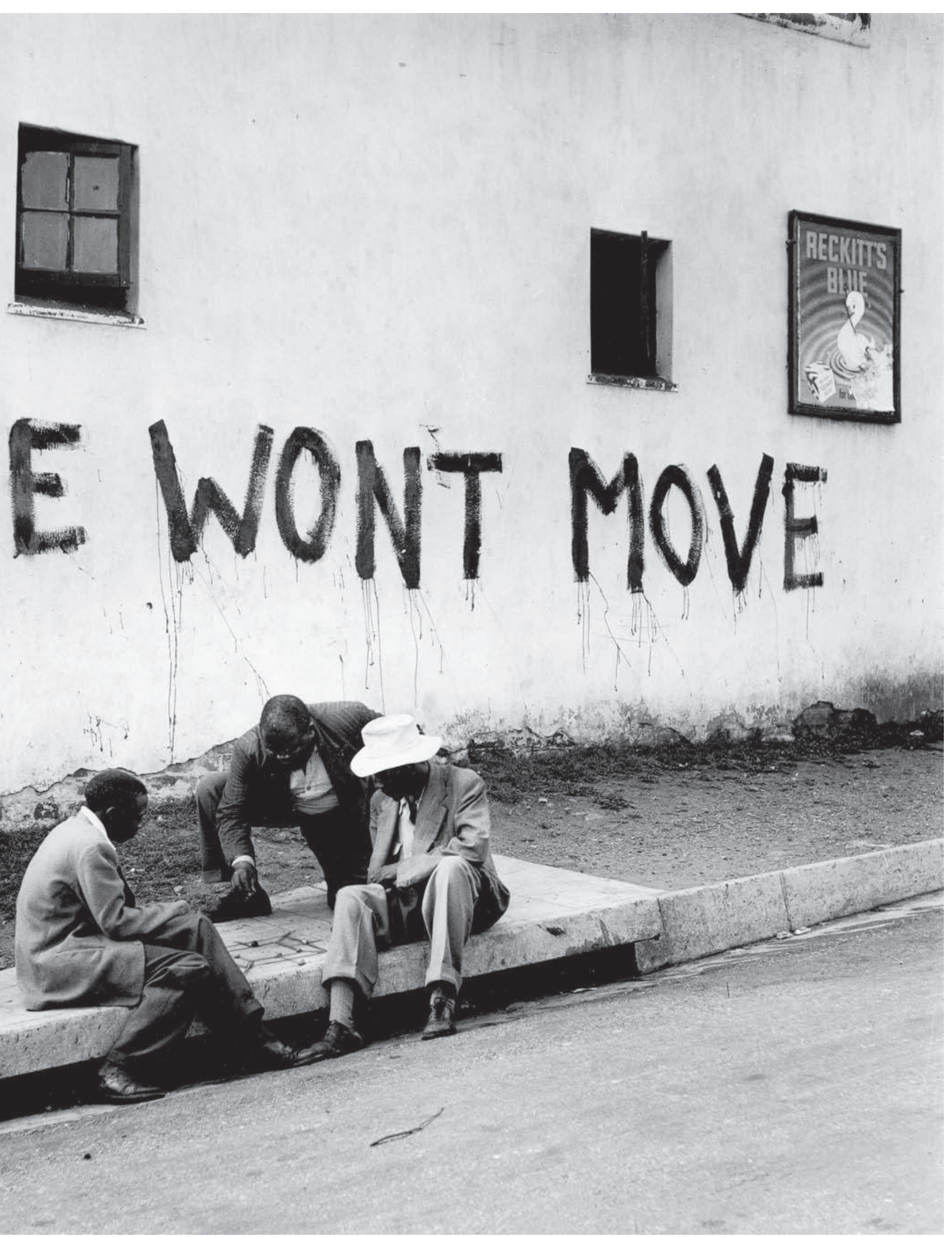


\section{Bibliographie}

Alexis, Jacques-Stephen

1957 « Où va le roman », Présence Africaine 13.

\section{BABA KAKÉ, Ibrahima}

1971 Glossaire critique des expressions géographiques concernant le pays des Noirs, d'après les sources de langue arabe. Paris, Présence Africaine.

BaBA KaKé, Ibrahima, MaQuet, Emma et Suret-Canale, Jean

1971 Histoire de l'Afrique centrale à l'usage des lycées et collèges. Paris, Présence Africaine.

\section{BIYIDI, Alexandre}

1955 «Afrique noire, littérature rose 》, Présence Africaine 1-2 : 133-145.

\section{Boubou, Hama}

1967 Histoire de Gobir et de Sekoto. Paris, Présence Africaine.

\section{CÉSAIRE, Aimé}

1955 «Réponse à Depestre, poète haïtien 》, Présence Africaine 1-2 : 113-115.

1956 Cahier d'un retour au pays natal. Édition définitive. Paris, Présence Africaine.

1959-1960 «La pensée politique de Sékou Touré », Présence Africaine 29.

1962 Toussaint Louverture : la Révolution et le problème colonial. Paris, Présence Africaine.

1979 «Léon Damas 》, Hommage posthume à Léon-Gontran Damas. Paris, Présence Africaine. 2005 Nègre je suis, nègre je resterai. Entretiens avec Françoise Vergès. Paris, Albin Michel.

\section{Cissoko, Sekéné-Mody}

1965 Documents d'histoire de l'Ouest africain pour l'enseignement secondaire. Le Moyen Âge : vVI $-x V l^{e}$ siècles. Paris, Présence Africaine.

1966 Histoire de l'Afrique occidentale. Moyen Âge et temps modernes, vIl siècle - 1850. Paris, Présence Africaine.

Colin, Roland

1957 Les Contes noirs de l'Ouest africain, témoins majeurs d'un humanisme. Paris, Présence Africaine.

\section{DAMAS, Léon-Gontran}

1966 Nouvelle somme de poésie du monde noir. Paris, Présence Africaine.
1972 Pigments - Névralgies. Paris, Présence Africaine.

Dione, Djibril et Cissoko, SekénéMody

1973 Histoire de l'Afrique. Tronc commun cours moyen. Paris, Présence Africaine.

Diop, Alioune

1947 « Niam n'goura ou les raisons d'être de Présence Africaine », Présence Africaine 1. 1949 « Malentendus », Présence Africaine 6. 1959 « $2^{e}$ Congrès, Rome $1959 »$, Présence Africaine 24-25 : 41.

\section{Diop, Cheikh Anta}

1954 Nations nègres et cultures. Paris, Présence Africaine.

1967 Antériorité des civilisations nègres : mythe ou réalité historique? Paris, Présence Africaine.

1974 The African Origin of Civilization. Myth or Reality, trad. en anglais (américain) par Mercer Cook. New York, Laurence Hill \& Company.

\section{Eboussi-Boulaga, Fabien}

1981 Christianisme sans fétiche : révélation et domination. Essai. Paris, Présence Africaine.

GIDE, André

1947 «Avant-propos 》,

Présence Africaine 1 : 6.

GLissant, Édouard

1969 L'Intention poétique. Paris, Seuil.

Hazoumé, Guy Landry

1972 Idéologies tribalistes et nation en Afrique : le cas dahoméen. Paris, Présence Africaine.

Kadima-NzUiı, Mukala

1984 « Message de la SAC », Mémorial international Frantz Fanon mars-avril 1982 Fort-de-France. Paris, Présence Africaine : 271.

Kesteloot, Lilyan et Котсну, Barthélemy

1993 Aimé Césaire, l'homme et l'œuvre. Paris, Présence Africaine : 203-204.

KI-Zerbo, Joseph

1957 « Histoire et conscience nègre », Présence Africaine 16.

1978 Histoire générale de l'Afrique noire. Paris, Hatier.
LAMARTINE, Alphonse DE

1850 Toussaint Louverture. Poème dramatique. Paris, Maison Lévy Frères.

\section{M’BoкоLо, Elikia}

1990 Éveil du nationalisme. L'Est africain aux $x \mid x^{e}$ et $x x^{e}$ siècles. Paris, Présence Africaine.

\section{Mudimbé, V. Y}

1982 L'Odeur du Père : essai sur les limites de la science et de la vie en Afrique noire. Paris, Présence Africaine.

\section{Mveng, Engelbert}

1972 Les Sources de l'histoire négro-africaine: depuis Homère jusqu'à Strabon. Paris, Présence Africaine.

SARTRE, Jean-Paul

1947 « Présence noire », Présence Africaine $1: 28-29$

\section{SengHor, Léopold Sédar}

1956 « Suite au débat autour des conditions d'une poésie nationale chez les peuples noirs. Réponse », Présence Africaine 5.

\section{Sylla, Assane}

1955 «Une République africaine au xIx siècle 1795-1857 », Présence Africaine 1-2 : 47-65.

TAMsir Niane, Djibril

1975 Le Soudan occidental au temps des grands empires ( $x l^{e}-x^{e} l^{e}$ siècles). Paris, Présence Africaine.

\section{TRAORÉ, Bakary}

1958 Le Théâtre africain et sa fonction sociale. Paris, Présence Africaine.

\section{WilLiams, Éric}

1968 Capitalisme et esclavage. Paris, Présence Africaine. 


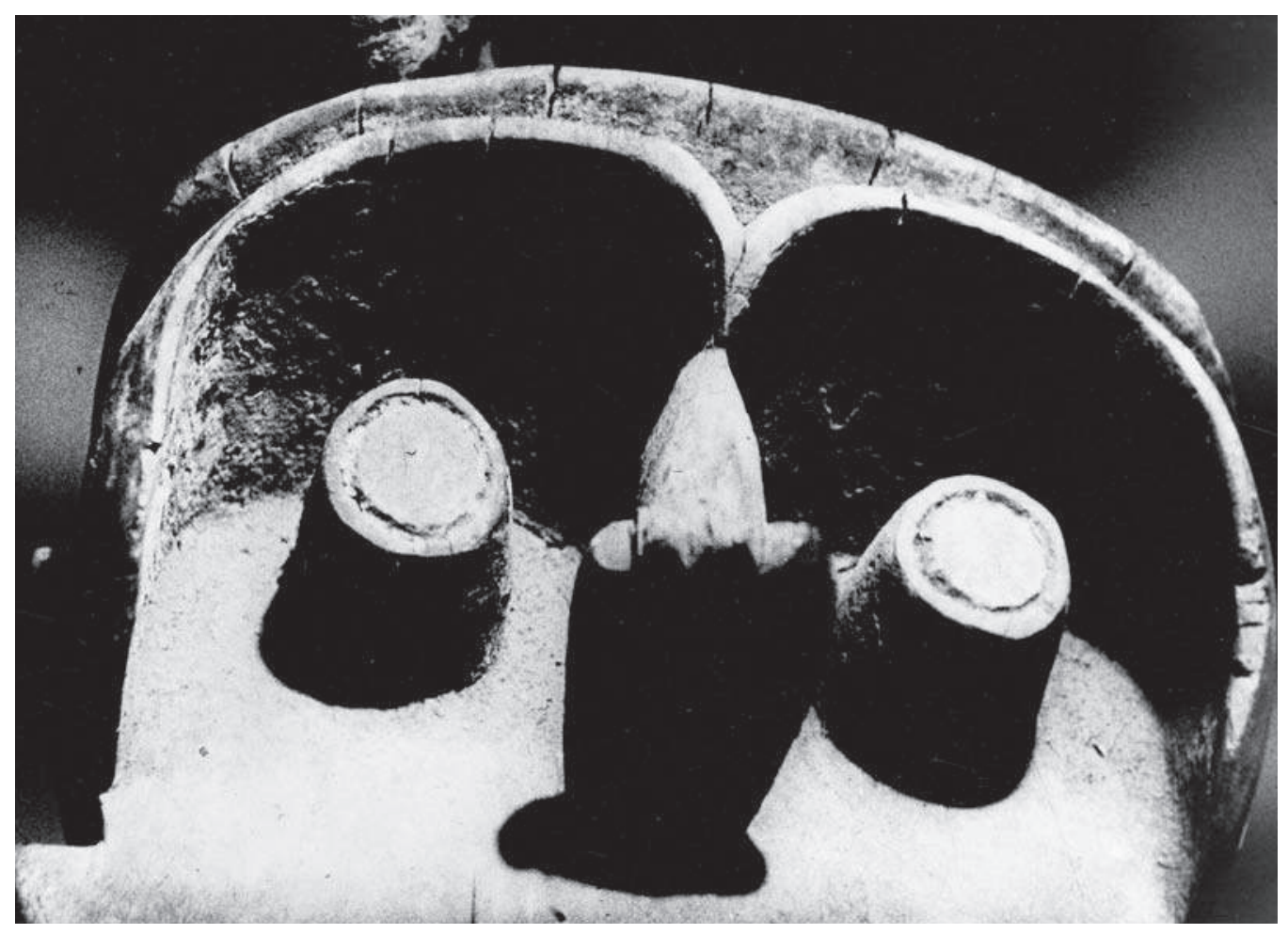

Fig. 9 Photogramme du film Lesstatues meurent aussi de Chris Marker et Alain Resnais, 1953. Iconothèque de la Cinémathèque française @ Présence Africaine.

\section{Résumé / Abstract}

Romuald Fonkoua et Marc-Vincent Howlett, La maison Présence Africaine - Créée par Alioune Diop (1910-1980), Présence Africaine est une entreprise à nulle autre pareille. Première revue littéraire et culturelle du monde noir à se maintenir sur une longue durée (depuis 1947), première maison d'édition africaine à s'installer sur le continent européen (dès 1949), elle est aussi le lieu de rencontre des intellectuels noirs du monde entier. Par l'édition de livres et la publication d'articles, Présence Africaine œuvre à la reconnaissance de l'unité et de la diversité du monde noir en suscitant l'émergence de nouveaux récits notamment dans les domaines de l'histoire et de la littérature. Des thèses de Cheikh Anta Diop aux travaux des historiens africains, une histoire de l'Afrique méthodologiquement exigeante s'y construit. Dans le champ de la littérature, Présence Africaine contribue à l'invention des classiques africains, au renouvellement de la création littéraire, et à l'émergence d'écrivaines. Elle favorise la circulation des $œ u v r e s$ littéraires du monde noir, par la traduction ou l'édition bilingue. Présence Africaine œuvre ainsi à la création des termes et des conditions d'une critique esthétique nègre, ainsi qu'à la fidélisation d'un public de lecteurs.
Romuald Fonkoua et Marc-Vincent Howlett, The Home of Présence Africaine - Founded by Alioune Diop (1910-1980), Présence Africaine is a venture like no other. It was the first black literary and cultural journal to have such a long run (it was founded in 1947). Présence Africaine was also the first African publishing house located in Europe, from 1949 onwards. The journal was a meeting point for black intellectuals from all over the world. Through editing books and publishing articles, Présence Africaine strove for the recognition of black unity, but also black diversity in the world through giving rise to the emergence of new narratives, in particular in literature and in history. From the Cheikh Anta Diop's thesis to the work of African historians, a methodologically demanding historical account of Africa was established. In the field of literature, Présence Africaine contributed to the invention of African classics, a renewal of literary creation, and the emergence of female writers. The journal promoted the circulation of black literary works, be it through translation, or bilingual editions. Présence Africaine worked towards establishing the terms and conditions for a back esthetical critique, and a loyal following of readers. 